\title{
SUPPLEMENT
}

\section{Responses to the 'Making Reality of Principled Common Programming' Document}

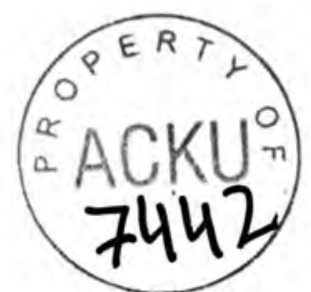

Islamabad, 17 July 1998 


\section{N T R O D U C T I O N}

\section{Dear Colleagues}

This volume contains further reactions to the document entitled 'Making a Reality of Principled Common Programming'.

The deadline for receipt of reactions was June $30^{\text {th }} 1998$, but as we have now received some important further reactions, these are being circulated to you.

This supplement includes reactions from:

Donors: The European Union, Japan, The Netherlands

UN: $\quad$ ILO, UNICEF, UNIDO

NGOs: $\quad$ DHSA, IAM, MEDAIR, Swedish Committee.

The previous compilation, circulated in early June, included the minutes of the London Afghan Support Group meeting as well as of common programme meetings in Herat, Jalalabad, Kabul and Peshawar, plus written reactions from:

Donors: Denmark, OIC, USA

UN: $\quad$ FAO, UNFPA, UNESCO, UNHCR, Mine Action

NGOs Afghan Disabled Society, AFRANE, AREA, CARE, DACAAR,

Ecumenical Programme for Afghanistan, Ibn Sina, IRC, Madera, MDM, MSF, NAC, SCF (UK), Swedish Committee.

Coordination:ACBAR, Islamic Coordination Council.

We are grateful to you for taking the time to respond. These reactions will be used as the basis for a draft common programming implementation plan. Initial thoughts on this plan will be discussed with you at the Mid Term Review Meeting, to be held in Islamabad on July $30^{\text {th }}$. Delays in responses to the document plus the current crisis facing assistance actors in Kabul have prevented the preparation and circulation of an implementation plan before then.

Thank you again for your continued engagement in this process.

Michael Keating,

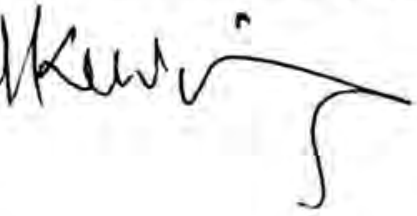

on behalf of:

Alfredo Witschi-Cestari

UN Coordinator, Humanitarian and Development Activities in Afghanistan 
Donors 
Islamabad, 3 July 1998

$41.6 .3 / \mathrm{wm} / 1520$

\section{Telefax}

Mr Alfredo Witschi-Cestari

Coordinator

UNOCHA

Islamabad

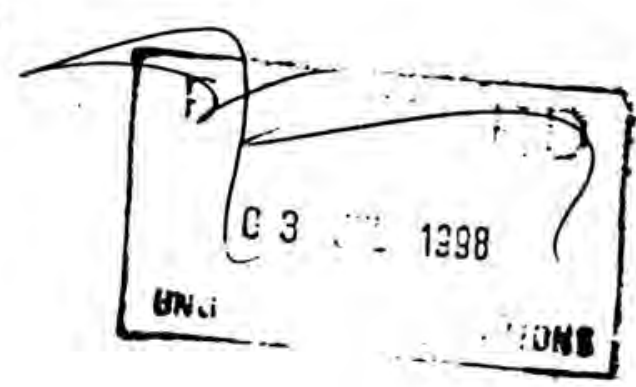

Dear Alfredo,

Subject:

Afghanistan - Common Progranuming Document

I am enclosing for your information an advance copy of the comments of the European Commission on the Common Programming Document and the Capacity Building Document.

These comments will be submitted formally by the Commission in the next few days

With best wishes,

Yours sincesely,

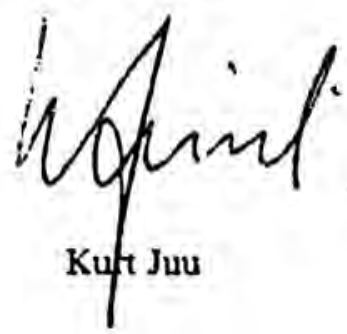

Encls:

Copy: Mr Michael Keating. C/O UNDP Afghan stan 


\section{COMMENTS OF THE EURC PEAN COMMISSION}

\section{COMMON PROGRAMMING DOCUM $3 N T$}

\section{GENERAL COMNEXTS}

The European Commission welcomes the propcsals contained in the LX: document on common programming which aim for a more inzlusive and transparent approach to the preparation of the Consolidated Appeal.

Given the complexities of the Afghan situation, tre aid community needs to craft a more common response aimed at improving the impact on the ground.

One of the most important advantages of this proposed pionecring exercise is that it involves donors in the strategic framework proce is and we all recognise that, though this. process will have to be built from the bottom up, donors have to give some direction to it.

This exereise is only justified if it adds value to what is already being done. The Commission's overall impression is that aid pro grammes in Afghanistan are now better prepared, better designed and better implementec and that there is a very sound basis to build for the future, In this context we do not dink that a fundamental recasting of the nature of assistance is needed. Any changes neec to be introduced gradually with the full consent and participation of all stakeholders. This will help to build confidence and preserve those good interventions, practices and arangements that are already in place.

However, the challenges should not be underestiniated and it is important to find the right pace. A major challenge will be to overcome the eluetance of $\mathrm{X}$ agencies themselves to work together within a commonly defined framework and to imiprove the quality of their management and human resources. There is litile indication that this can be achieved easily, particularly if it is not effected voluntarily but has to be imposed by burenucratic diktat. A more coherent approach of the $(X \mathrm{maj}$ take many years but pressure will have to be maintained on LX agencies. Also, the IXYGO coorrdination will have to be enhanced and perhaps modified.

\section{SPECIFIC COMMENTS}

\subsection{Management Architecture}

2.1.1 A point to be clarified is the composition of the Afghan Programming Board (APB) and the Regional Co-ordinatior Bodies (RCBs).

APB The European Commissior participation in this body is yet to be defined. In the original version of the document it was suggested to limit it to the ASG troika with no Commission presence (in spite of being the major donor) or guarantees of a European piesence (it has to be bome in mind that 6 non European countries are membe)s of the ASG. therefore the possibility exists of a non-European troika). V.oreover the participation of all the $L . X$ agencies in the APB seems a bit exce! sive (the NGOs will only be represented by co-ordination bodies) and will m.kke it difficult to work. They could be simply represented by the LX Reside: $2 t$ Coordinator. 
RCBs These should be kept fairly small to be operational. In case this is difficult to achieve, there may be a need for two types of composition: one. where all local actors would take patt and which would meet periodically and another formed by a small number of people whe would prepare the decisions to be taken.

2.1.2 Regarding the mandates of these bc dies, it should be taken into account that many participants in both APB and FCBs may not have full authority and need to refer to HQ on some issues. This is certainly true of most donor representatives and local NGO persennel who will be unable to commit the ir organisations.

The same problem arose at the tim: of forming the Task Force, when the Delegation insisted on the removal of the word "representative" from the initial document. In the end, it was understood that Members contributed on the basis of their personal and professional capacity and their position $v i s-a-r i s$ their headquarters was not comprom sed. But the functions proposed for the APB and the FCB's are at another level and the pragmatic approach might not be enough. Therefore, we propose thit these functions should be clearly stated as advisory

Part of the problem is the dogmatic st: te of the definitions of the mandates and tasks of these bodies. Elsewhere in ine paper, there are clear indications that these are expected to be aspirational nt ther than operational in the first instance and that a long period of experience and mutual confidence-building will be sequired to achieve them. It might be better if some of this language was used to introduce the definitions and to set them in a less dogmatic context.

Regarding RCBs, we suggest that they should concentrate on capacity assessment, information sharing and developing regional strategies rather than analysis of individual projects which would only generate inefficiencies. In our case it is only the Commission that can decide whether or not to commit funds.

On the other hand, there is littie indic stion of a mechanism for co-ordinating between the RCBs to prevent entirely e ifferent positions being taken in each of the regions because of the personal app roach of individual RCOs

\subsection{Afghan involvement in the process}

Another area of concem is the relationship of Afghans to the Common Programming Structure. It is not always clear whether the report is referring to Afghan NGOs participating in the programme, Afghan eitize: 15 benefiting from it or the presumptive Afghan authorities. (Presumably 5.1 intends ise Afghans to assume responsibility for the sustainability of project activities, not for common programming).

Various references to contact with the authurities appear to leave unresolved the conflict between the need to avoid recognition or institutional strengthening of the warring factions and the desirability of supporting the maintenance and development of the available skills in what is left of the former public service system. The suggestions for the RCBs approach to the plesumptive authorities could lead to a continuation of the fragmented and contradistory approaches that have led to the current impasse. The L.N.Taliban Technic d Committee appears to have been forgotten. 
Our view is that though local authorities should be kept informed by RCBs they should not be full members of these bodies. This view is reinforced by the fact that many authorities view agencies as a souce of favours and funds and are not interested in working with them in projects a td programmes.

On the other hand the role of Afghan NGOs and the local communities themselves is crucial if local capacity building is to be pusued. Therefore they should be ciosely involved in this $C P$ process.

\subsection{Consolidated Appeal process and l'rogramme cycles}

The Commission is clearly moving towards longer term funding for programmes projects. In this context, the juestion arises as to how to make this compatible with the Annual Consolidated ippeal process On the other hand. the "approval cycle" may conflict with the proc sdural requirements of DG IB, DG VIII and ECHO. Certainly ECHO would not wisis to be precluded from providirg a rapid response in some cases by the need to await approval from the Common Programme Strueture. It may well prove difficult to fit the Commission s procedures into the time frame envisaged for the preparation of the Cinsolidated Appenl

Therefore $t$ is necessary to recognise the feedom to work in parallel with the CP process or outside it.

\subsection{Scope of CP}

It goes without saying that the credibility of this process is intimately linked with success in its implementation. The added layers of decision making will sure increase overall bureaucracy and probably generate inefficiencies in a first phase. Therefore in the London ASG, the Commission sugge ited that Common Programming should star around particular issues and specific places. This idea was supported by Mr Alfredo Witschi Cestari who suggested that, in the furst phase, the CP could start for Banayan,'Hazarajat region. We would reiterate here our suppon for this idea.

\subsection{Monitoring and Evaluation}

We fully support the intention to upgrade $M \& E$ and that this should be carried out by an incependent and autonomous team that would carry out a system-wide assessment. The paper on Monitoring anil Evaluation is excellent. but it is not absolutely clear that the methodology proposed will ensure the independence of the monitoring body: The paper also to some extent side-steps some of the issues which could arise in following the proposals for coordinating existing monitoring and evaluation standards and practice. The initial review of all internal and extemal evaluations to be undertaken in 1997 and 1.398 would require the agreement of the agencies which authorised them and this cculd be particularly difficult for internal evaluations.

In conclusion, the paper provides an excellet it basis for approaching the task, but the next stage will require some difficult polity, resource allocation and operational decisions by donors, both individually and cellectively.

However, the maintenance of a central depo itory of $M-E$ reports could raise issues of cliend/consultant confidentiality in some cases. 


\section{OTHER COMMENTS}

Under "Operational Guidelines", the phrase "organised in pursuit of the overall goal" of gender equality, suggests that only pr jects primarily and directly promoting equality can be included. Something like "w ith full respect foricommitrnent to might be better.

There is a typing error on P9 (4.3 C mmon Services: transfer of cash) "information" banking channels should pres imably be "informal".

Finally, I would like to underline that none (f these comments is intended to indicate any lack of commitment to the Common P.ogramming approach, rather to point to the need for a pragmatic and realistic approach in the early stages and to areas where the Commission needs to be clear on the oferational and policy implications of the current document. 


\section{CAPACITY BUILDING DOCUMENT}

The paper is analythically extremely rich ald well written. The Commission can subscribe to its conclusions, namely that assistance can be provided on a community. by community basis, developing a non-in ititutional capacity at the local level Besides, this approach would be consistent with our principled approach

This approach, however, does not address th: problem faced in the cities, especially in Kabul where the notion of community is different and where international aid providers replace the authorities and assume he role the latter should play (e.g. water and sanitation in Kabul).

Another consideration is what will be the reaction of the Taliban if aid is reduced in Kabul. Retaliations against semaining aid providers have to be taken into consideration.

Equally, it seems clear that the understandir $\mathrm{g}$ by the Taliban of international aid is more influenced by their desire to obtain control of resources than concern for community welfare. The impact of capaciy-building at community leve! on the progressive empowerment of individual citizens could then lead to conflict with the Taliban, (and not only them), but it could al:o plant the seeds for the evolution of a more responsive and acceptable system. It is perhaps a risk that is worth taking with our eyes open. 
Comments of the Japanese Government to the UN document "Making a reality of Principled Common Programming".

\section{(General Comments)}

1. With reference to the section 1-3 in the above document, implementing the Principled Common Programming, we can expect enhancement of an aid efficiency through strengthening of collaboration among aid partners for Afghanistan such as donor countries, international organizations and NGOs. The Government of Japan finds the idea very interesting in the course of UN reforms and supports its implementation.

2. In addition, it is important to take into consideration an aspect of confidence building between aid partners and Afghan people in addition to the improvement of aid efficiency in implementing the Principled Common Programming.

3. We should make sure that opinions of UN organizations be due coordinated and different opinions not hinder smooth implementation of the Principled Common Programming.

4. When it's required to change mandate, organization, budget and staff allocation of UNOCHA and other coordinating organizations in the future, it should be discussed among the partners concerned. In this context, it's significant to take some measures, which accelerate efficiency of activities such as establishment of UN organizations' common field office requested by Canada in the 3rd ASG meeting in May 1998.

5. It's too early to put into practice the idea of "common funding" that has been discussed in the occasions such as the second ASG in December last year, as the Principled Common Programming itself is still being discussed. 


\section{(Comments on the APB and RCBs' organization and their roles)}

6. With reference to the section 4.4 and 6, as Afghan Programming Board (APB) is placed as the supreme decision making organization, it's vitally important to secure APB to be organized which reflect the opinions of donors including the consideration of attendance of troika countries (ASG former, present and next chairman) and establishment of Thematic Group. It's necessary, based on the aid partners' opinion, to reach a conclusion on this point, when APB will actually be established.

7. With reference to the section 4.2 and 6 , participation of representatives from donor countries should be secured in the Regional Coordination bodies (when it's necessary) to reflect the opinions of donors.

8. With reference to section 4.2, while it's stated that participation to ASG are limited to donor countries, which have consistently been supporting UN consolidated appeals, the Government of Japan requests the detailed information of the discussions about that decision.

(Comments on the consolidated appeals, and aid project formulation and implantation)

9. With reference to section 4.1, 4.4 and 5.3, consolidated appeals to support Afghanistan will be formulated based on the process of RCB's recommendation and adoption by APB and donor countries are expected only to contribute to the projects mentioned in the appeals, however, it is also adequate to formulate some projects such as Afghan Refugee Repatriation Project to Azra and Tidin Districts, in close cooperation of international organizations and each donor country, as it is in line of the concept of the principled Common Programming. Although consolidated appeal will continuously be issued once a year (October), it's necessary to revise it when the situation is drastically changed. 
(Comments on share and control of information)

10. With reference to section 4.3 , as to the share and control of information, it is important to take into account the reports which will be issued such as the reports of UNSMA on political situations. If there exists the reports in some fields (for example : UN Secretary General reports on Afghan situation), they should be utilized.

(Comments on the relations of neighboring countries and NGOs)

11. With reference to section 5 and 6 , neighboring countries surrounding Afghanistan (non-ASG participants) and NGOs' roles are mentioned in connection with the implementation of the Principled Common Programming. Have those countries and NGOs been given enough explanation about discussions on the Principled Common Programming? Furthermore the Government of Japan wants to know whether UN finds it possible to have their participation to the Principled common Programming. 
Dear Mr. Witschi-Cestari,

During several occasions the Netherlands has indicated to be a strong supporter of the process that aims to realize a strategic and coherent approach of the international community in its dealings with complex emergencies, including the one in Afghanistan. It is the view of the Netherlands that common programming should be a crucial operational element to that, as Minister Pronk expressed several times and confirmed during his latest visit to Afghanistan in February 1998 and in his interventions during the Afghanistan Support Group meeting of 5 May. In that respect I would like to reiterate the comments in my letter of 19 November 1997, containing some observations and comments on the state-of-events of the Strategic Framework process at that moment.

In general the document that has been presented to the aid community is clear and concise and a useful attempt to win the cooperation and commitment of all stakeholders in an even better coordination and use of experiences, capacities and resources to improve interventions in the complex situation in Afghanistan. The proposed institutional arrangements and substantive elements of common programming that should be agreed upon and - more importantly - should be adhered to are acceptable to the Netherlands. I would like to stress that all relevant stakeholders should strive to act as equals in delivering a common programme, for which in some cases capacities will have to be built and more transparency should be sought after. The consequences in terms of donor responsibilities (p. 16 of the document) are also acceptable and have been expressed by representatives of the Netherlands during several occasions.

To: Mr. Alfredo Witschi-Cestari

UN Coordinator Afghanistan

UNOCHA

House 293, St. 55, F-10/4

Islamabad 
In terms of impact-oriented programming I would like to mention some issues for which there is room for more elaboration. In the first place - as is generally known - the Netherlands attaches much importance in providing aid with a view to contribute to peacebuilding. Although expectations should not be too high on the potential of peace promoting aid activities, programming should take place with the potential of peace-building in mind. Furthermore, the way in which needs are being expressed by the Afghan people and assessed by them and the aid community will need a lot of attention and we subscribe to the proposals to make this a participatory process. Finally, monitoring and evaluation should result in confidence among all that common programming is being undertaken with a view to an efficient and effective use of resources, whereby the highest impact possible of the interventions is being guaranteed.

I trust that the aforementioned observations and comments serve the purpose of expressing the commitment of the Netherlands to be a strong supporter of common programming. With pleasure I have taken notice of the fact that the first steps to make common programming a reality have already started in Afghanistan and Pakistan, initiated by UNOCHA's advisor on common programming and the regional coordinators and look forward to a swift implementation by all players involved.

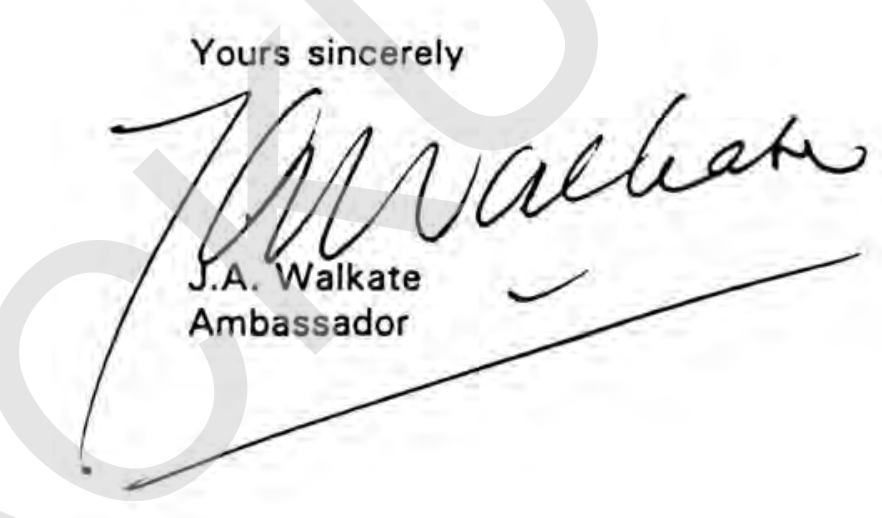




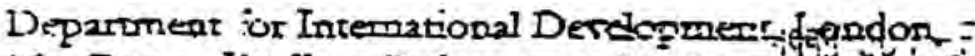

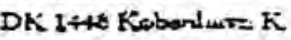

Denrrivate

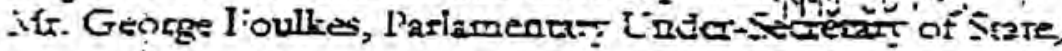

Pleone tes 5 is 52000

Famo.: + 41719170016

$F=4532540533$

Earit: Gumdk

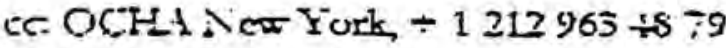

Tota 3232 EIR LKK

Cables Exuingerss

\section{TELEFAX}

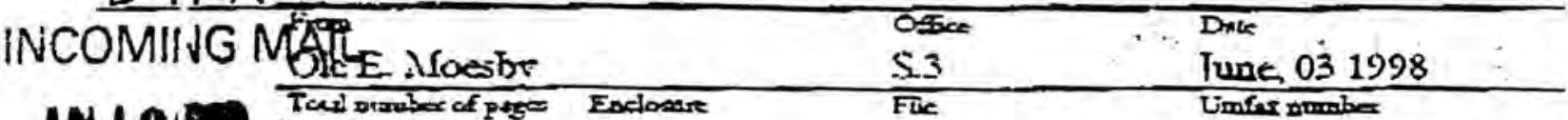

\begin{tabular}{|c|c|c|c|}
\hline . & 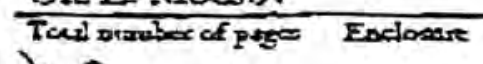 & Fue & Limfers number \\
\hline & 丸2 & $\begin{array}{l}\text { 46. Afghanistar } \\
5 . \mathrm{b}\end{array}$ & 3954 \\
\hline into conv 10 . & PLoDe- & $\mathrm{F}_{2 \mathrm{x}}$ & \\
\hline
\end{tabular}

\section{Principled Common Programming, Afghanistan}

Dear Sir:

The Presidenct has asked partiers for comments na the proposal of the tרi coordinator in Islamabad for a Priacipled Counmon Programming.

Demark supports fforts towards a better co-ordination and a privipled centrod spproach in the aid to Afghanistan Deumark welcomes the proposid for Prineipled Common Proganming (PCP) as an impoitant siep in this direction.

It is imporant Jaat donors continuously express their fill support for the process of the PCP. Therefore Denoratk wish that the support expressed by the donors at the Af frtan Support Group meering in London I Mar 1998 be reiterared in the common tesponse to tive UN Emergenty Relief Cororöinator.

Dermark has the following comraents to the Principled Common Pro gramme:

1. The quastion of assuring donors" irfluence in the Afghamistan Progromming Board (APB) has to be further discussed.

2. The PCP suggers thar Regivirl Coordinating Bodies (RCB) work on the basis of consersus-Denmark recommends tar a conflict solving mechanism is ser up, in under to asure the workability of the RCB's. 


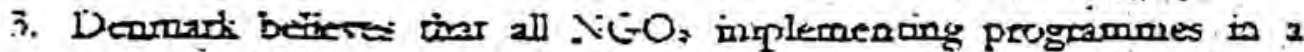
regios should hare the to to be nerrbers of the RCB. In general it is iomportar tor the NGO involvement in the whole process is assured

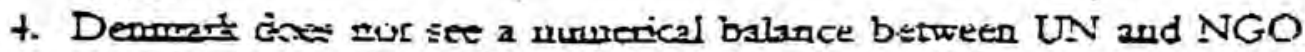

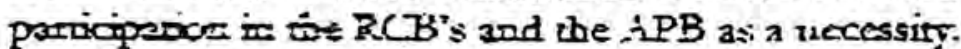

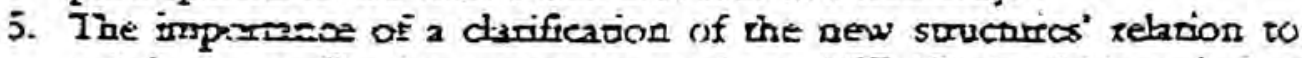
exiscing co-orwination scructures such as ACB.AR should be emplansised in order to avoid thar the neviv, structurs lead to unnecessay bureaucrant.

6. Given the purr securiey situsrion for aid rorkes in Afghanistan Denmark recommends that more atrencion should be dexwn to this issue both in the sense of assuring a common approach and in defining the LiN's role in case of as evacuarion of aidworkers.

Denmark is looking formand to be involved in the process of the further developiluent of the Principled Comruon Progamme:

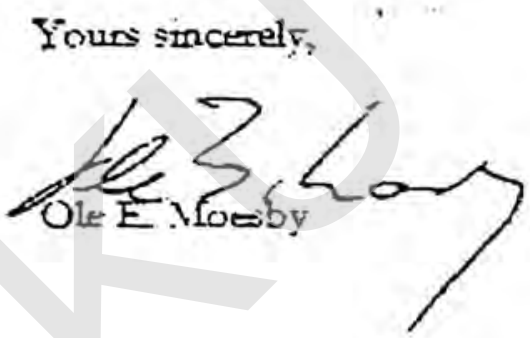




\section{UN Agencies}




\section{INTERNATIONAL LABOUR ORGANISATION}

AREA OFACE POR PANESTAN AND AFGHANESTAN

58, Khayaban-e-labal, F8,2, P.O. Box No. 1047, Islamabad (Pakistan)

Tel: (92-51)-854804, 255950 Fax: (92-51)-260662, 859278 E-mail: islamabad@iloisb.org.pk

To: Alfredo Witschi-Cestari, UN Coordinator, Afghanistan

Copy: Mikael Keating, Coordinator, UN Common Programme Afghanistan, UNOCHA

From: Dani Appave, Director, no Islamabad

Our Ref: AFG - GEN

Date: 04.07 .98

No of Pages: 1

(incl this page)

\section{Subject: UN Common programme Afghanistan}

Please find herewith the ILO comments to the UN common programing document. We regret the late response, but hope nevertheless that these comments/ considerations can be incorporated in the document.

overall comment: There should be a reference in the document to respect for human rights, including freedom of association, non-discrimination, and elimination of forced labour and child labour.

apecific comments:

p.5: In view of the high priority the ILO puts on gender equality and non-discrimination issues, reference should be made to ILO conventions, in particular $c .100$ and 111 . (both have been ratified by Afghanistan).

p.14: The social partners are important members of civil society and should therefore be included as potential beneficiaries.

P.20: The section on the social and humanitarian situation refers mainly to the health sector. Mention should also be made of other important areas such as improving functional literacy, training (inel. vocational), employment, incomes, and women's participation.

\footnotetext{
With best regards,
} 
monitor and evaluate the progress we make. Such indicators could be very useful as criteria to judge trends in the cooperation of the local authorities and in their actions to reduce discrimination. The indicators would also help the aid community recognize and deal with deliberate violations of the agreed principles.

We recommend that the Convention on the Rights of the Child be included in Item 1 as one of the UN human rights covenants and conventions by which delivery of the international assistance for Afghanistan should be guided. It is our common responsibility to advocate for and promote the Convention on the Rights of the Child. This Convention, signed by the state of Afghanistan in 1994, should be an important conduit for addressing our common concerns for the rights of girls to basic services such as health care and education.

With regard to the coordination mechanisms and a common framework for programming, we would like to make the following comments:

1. UNICEF supports the active participation of donor governments and organizations at all stages of the "Principled Cormmon Programming" process. We hope that a "Principled Common Programming Framework" would effectively serve as a forum for free interaction and dialogue with all actors and stakeholders of the assistance for Afghanistan.

2. Common planning and programming starts when all actors and stakeholders agree upon programming priorities. They should also see to it that the principles and the operational guidelines as outlined in the document are adhered to in the formulation of their specific programmes and projects. However, the opportunity for each agency or organization to contribute its input to this process according to its mandate and global priorities should not be precluded. The "Regional Coordination Bodies" (RBCs) and "Afghanistan Programming Board" (APB) should facilitate the: coordination of activities, rather than straightjacket them. This framewo-k will ensure that the diversity in mandates, niches and comparative advantages of each agency or organization are considered as a value added to the process, not as a detriment to it. In this regard, we believe it is of critical importance to make use of, and build on, existing mechanisms as part of the Resident Coordinator System and the country team wherever practical. We need to avoid a proliferation of UN coordination mechanisms carrying out similar functions.

3. The "Principled Common Programming Framework" should also go beyond this. It should also provide a forum and/or mechanism, (at locally and national levels) through which the Resident/Humanitarian Coordinator can forge a commitment on the part of UN-agencies, donors and other actors, to commonly agreed recommendations. This will be particularly important in dealing programmatically with actions by local or other actors that run counter to the goals set for our "Principled Common Programming". We must beware, however, that the common programming exercise could become somewhat 'top-down'. We must clearly show, as we finalize the 


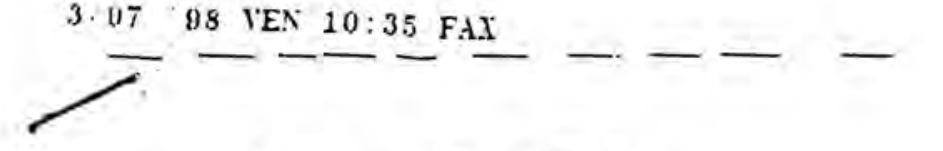

\section{unicef (s)}

Geneva Office:

$$
\text { Auc/Mk }
$$

Liniced Nation, Chisdren's Fund

Fonds de: Nations Unies pour l'enfance

Fonde de las Nisiones Linious para la Infancia 30 June 1998

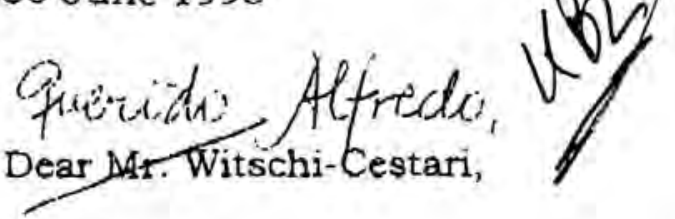

Ninuvelle adresse :

Visileurs : 5-7. at de la firis

Teléphune 909 51 i]

reiex +15432 IICT CH (in thanger

Telefax 9(1) 59 no $0 \mathrm{COQ} 9005001$
Bureas de Genève

Palais des Nations

$\mathrm{CH}-1211$ Geneve 10

Visiteurs: Av: Trembley in

Telephone 708 $585(1)-98 \times 400$

Télex +15434 LCF $C$.

Teleitio $7010822=$ GCO 791 (1) 95

Thank you for sharing a copy of the document "Making a Reality of Principled Common Programming" for our comments. As you are aware, at various pcints of time in the past, UNICEF contributed its input either in the process of drafting through the Afghanistan Programme Office or through the headquarters divisions in the ECHA and IASC discussions. Our views on the broader process for responding to the situation in Afghanistan, of which this document is an integral part, have also been expressed at various sessions of CCPOQ, ACC OC and ACC. The relevant conclusions and recommendations of these groups should also be reflected in this current document. Finally, we believe the principles and approaches to common frameworks developed by the UN Development Group in its preparation of the UN Development Assistance Framework (UNDAF) will have broad applicability to any comparable instrumejt for post crisis rehabilitation. This time we have taken a fresh look at this document, taking into account the visit of Executive Director to Afghanistan in April and the participation of Dan Toole, her Chef de Cabinet, in a series of negotiations with the Taliban in May. We have also considered the major decision/action points emanating from the Afghanistan Donor Support Group Meeting held in London on 5 May.

First, UNICEF would like to thank you and all others who were involved in preparing this document which proposes mechanisms to improve coordination and provides a framework for more coherent programming for Afghanistar. In our view, the document lays out the basic elements that the UN team and the aid community as a whole can adopt to improve the impact of assistance and make concerted efforts to attain common objectives.

Indeed, a common framework for programming can ensure an efficient and effective way to deliver assistance towards the ultimate goal of international assistance for Afghanistan, namely,

- alleviation of human suffering;

- protection and advancement of human rights, with particular emphasis on gender issues;

- the provision of basic services;

- the protection, creation and sustainability of livelihoods.

We believe this common programming framework could benefit from stating these goals explicitly as the rationale for the international assistance for and with the people of Afghanistan.

We are in agreement with the six elements outlined as "guiding principles" for international assistance for Afghanistan. We would also appreciate if measurable benchmarks/indicators could be developed as soon as possible to 
document, how the common programming will lead to improved support to the affected populations throughout the country.

4. The authority invested in you, as the Resident Coordinator, allows you to establish local geographical or thematic/sectoral theme groups, reporting back to the meeting of the whole. In the current draft, these groups are called Regional Coordination Bodies, with the national entity called the Afghanistan Programming Board. These bodies should assist us to work together to fully realize the above vision. I would propose, however, that the word "Board" be reserved for the governance functions exercised by memtier states over UN organizations, programmes and funds. This forum could thus be called the Afghanistan Programming Task Force. Some of the options and specifications proposed in the document as to numerical restriction and chairmanship arrangements, could actually be considered restrictions to the established authority for Resident Coordinators. As this is not a governance board, the option for numerical restriction could hinder you to use the Afghanistan Programming Task Force as a forum to build a concerted effort with all key actors. You can count on UNICEF to fully support your effort "that the assistance community acts in a coherent fashion". We believe this process can improve coordination and bring about greater synergy among indiviclual agencies and other organizations including NGOs, and protect and support the responsibilities of each agency or organization through mutually supportive principled approach.

5. The suggestions in the planning process are already largely compatible with our procedures and are in line with the Secretary-General's reform agencla for improved and more efficient UN work. The intersectoral and areaspecific- aspects are also important. Common services, vehicle policy, security and communication make good sense, are part of the reform process and should be pursued wherever feasible.

6. From the operational agency's point of view, the issue of inputs by each agency or organization that reflect its mandate and global priorities remains a cornerstone. At regional level, for example, where the assessment of needs; and the formulation of projects and activities are carried out, each agency, while coordinating its inputs at regional level, would ensure that the regional priorities do not conflict with the agency's mandate and global priorities. Each agency would ensure that its own priorities are in turn adequately reflected in the regional priorities as defined in agreement with its partner agencies and the local authorities/communities. As an important tool of coordination, particularly at regional level, we recommend that we study, modify and support the existing sectoral "Technical Working Groups" (TWGs) to form the foundation for RCBs. Our past experience shows that the TWGs served as an effective coordination mechanism within programme sectors at regional level among UN agencies as well as with NGOs.

7. We believe the UN coordinator must be supported by a Secretariat to the APB for the "Principled Common Programming" process. Regional Coordinators will also have to be carefully selected: the degree of success in 
our work at the regional level will depend on the experience and the ability to build consensus among these Coordinators.

8. We believe that involvement of the Afghans in the process as far as possible will be a key to the successful implementation of the proposed system of assistance. Community members or technical staff of local authorities should be brought in at the regional, provincial or district levels and much less at national level where things tend to be more political. National UN and NGOs staff could also be more involved in the processes. Women's involvement in planning is mentioned at one point, but it is could be rnore closely followed up in the document. Given the many challenges, it might be useful to be more explicit, perhaps with examples, on how women's involvement will be regularly supported. However, in pursuing this goal, we will need to tread the balance between support for Afghanistan and standing for the guiding principles vis a vis authorities who at times do not fully live up to their state responsibilities.

We hope you find the above comments useful. We are pleased that you are involving the country teams in the process of finalizing the Principled Common Programming document. We will seek to ensure our full and committed participation in it.

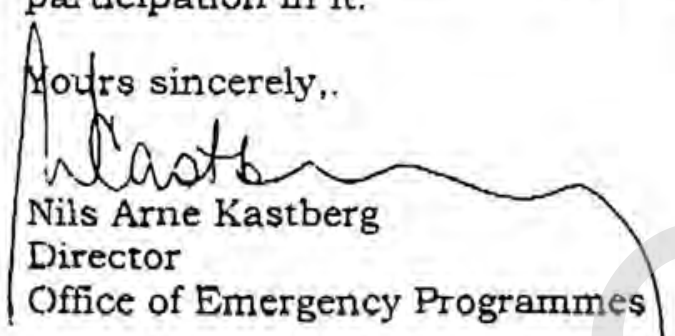


Mr. Michael Keating

Senior Advisor

UNDP Afghanistan

\section{Subject: Workshop in Bamyan}

Dear Mr. Kearing,

Let me take this oppottunity to congratulate you on your Common Programming initiative witl respect to the Hezarajat region.

UNIDO, being an implementing agency of the United Nations system, witb the mandate for ustainable industrial development, feels that we can substantively contribute towards the Common Progranme. However, as the UNDO Islanabad office only recently received official authorization from headquarters to cover Afghanistan, we are presently operating under certain constraints, one of thom being the absence of a travel budget for the professional staff.

We would appreciate UNDP's cooperation in this unatter, thereby allowing UNIDO to contrifute at the subject workshop and ensuring a Cornmon Programme, not only ju coucept, but also in practice.

Looking forward to your response, we remain,

With best regards,

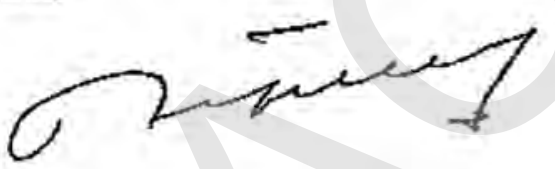

Dr. R. G. Gumen

UNIDO Representative Islamalad

Pakistan. 
NGOs 
Headquarters - St 13, Wazir Akbar Khan, Kabul, AFGHANISTAN ونتر مركزي - سرك ل1 ، وزير اكبر خان ، كابل - افغانستان SATCOM Fax: 873682340252

To Jolyon Leslie, Regional Coordination Officer, UNDP Kabul From Tim Aldred, Donor Relations Officer, IAM

21 June 1998

Dear Jolyon,

\section{1998 Consolidated Appeal}

I am pleased to inform you that all LAM programs submitted to the 1998 Consolidated Appeal have now received enough actual funding or funding pledges for successful operation until the end of 1998. I have attached a summary of donations/pledges to this letter. I would be grateful if you could inform the Appeal administrators accordingly.

\section{Common Programming}

Thank you for all your work in facilitating this process, and for the opportunity of last week's workshop. I will be putting together a written response for IAM as a countrywide organisation in consultation with Bruce Gibbs and other senior staff in time for the June 30 deadline. As you know, some other NGO agencies are responding very negatively to the CP document as it currently stands, primarily concerned with issues about NGO autonomy. IAM of course retains specific issues of concern, but our preferred way of expressing these will be to remain within the $\mathrm{CP}$ process and seek to influence things from there.

\section{Change of IAM Personnel}

As you know, I will be leaving Kabul at the end of July, mainly in order to get married! I can formally inform you that taking over my role as Donor Coordination Officer will be Brenda Aldrich. I anticipate that she will include within her responsibilities interagency work on CP.

With appreciation of your continued partnership,

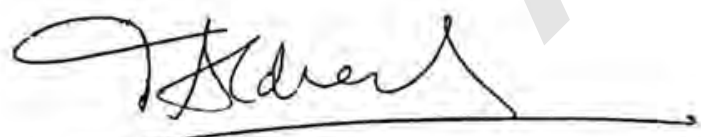

\footnotetext{
Tim Aldred

Donor Relations Officer
}

cc Programs listed in the 98 appeal, relevant directors, Brenda Aldrich 
MEDAIR Afghanistan

House 68, T Lane, Street 15

Wazir Akbar Khan

Kabul, AFGHANISTAN

Int'l Tel: +873682286520

Int'l Fax: +873682286522

Mr. Michael Keating
Senior Advisor, Strategic Framework for Afghanistan
UNDP, Islamabad

June 21, 1998

Dear Michaei,

I write in response to your request for feedback on the document "Making a Reality of Principled Common Programming." I would like to surround the comments below with an affirmation that MEDAIR is firmly committed to coordination in all of its work, and will do all that it can to contribute to the success of future coordination efforts in all provinces and sectors that we are involved in. At this time, and assuming that the following concerns will be able to be addressed, the most likely vehicle for coordination seems to be a modified version of the Principled Common Programming, and as such we look forward to the continuing dialogue concerning it.

1. MEDAIR has purposefully maintained it's regional head office in Kabul in order to remain closer to, and more interactive with, our Afghan beneficiaries. It seems clear already however, that the Common Programme will be based outside of Afghanistan, and led by those based outside of Afghanistan. We feel that this is NOT a helpful situation and will simply reinforce the current negative status quo, which has somehow established Islamabad as the centre of the Afghanistan humanitarian effort. Practically this concentration in Islamabad will limit the involvement of those of us, both Afghan and expatriate, based in country. It would give a very strong and positive message to all involved, and especially our Afghan colleagues and critics, if we could base all Common Programming activities in-country.

2. The Common Programming document mentions the UN agencies' independent mandates, and passing reference is made to ICRC's unique mandate. However nowhere is it recognised explicitly that NGOs have mandates that are different both from the UN and ICRC, and from one another. We are Non-Governmental, not because we do not want to co-operate with each other, but because we also have unique mandates and we seek to maintain those mandates, independent of any outside interference. ICRC is strong enough to resist being co-opted into the Common Programming, and thus is guaranteed the ability to react independently, It is unclear how the rest of us will fair. It is however of utmost importance to us that we retain the prerogative to take decisions independently, without the threat of being penalised in some way. 
3. It is a concern for MEDAIR that this effort is being so clearly UN lead. It is acknowledged in the document that the UN agencies need very much to coordinate their own inter agency work, which we agree with. Recent history has also shown a not-always well thought out programming tendency amongst certain UN agencies. Also UN agencies (in Kabul at any rate) arc often mandated to work through the authorities, causing a dilemma when the preference of any particular authority conflicts with an NGO's mandate. Furthermore the UN is clearly a political organ, and it's agencies are subject to the changing policies of member states and decisions taken in New York, Geneva, Rome, etc. Strong UN leadership would leave NGOs, and their programmes, vulnerable to decision makers where our influence is very minimal. Finally it is questionable whether the UN bureaucracy is flexible and responsive enough to respond appropriately and to the very dynamic situation in Afghanistan, especially if it is "burdened" with a wider co-ordination role. Based upon the above, it is worrisome that the UN should be leading an attempt to co-ordinate all humanitarian activities in Afghanistan, and particularly that all funding requests should be forced through a UN organ (the consolidated appeal).

MEDAIR remains highly committed to professional information sharing and coordination in our work. We are also committed to implementing needs based programming. As such, we will continue to invest in the process of Principled Common Programming to the best of our abilities, especially on the Kabul level, and as long as this does not prove detrimental to our work in Afghanistan.

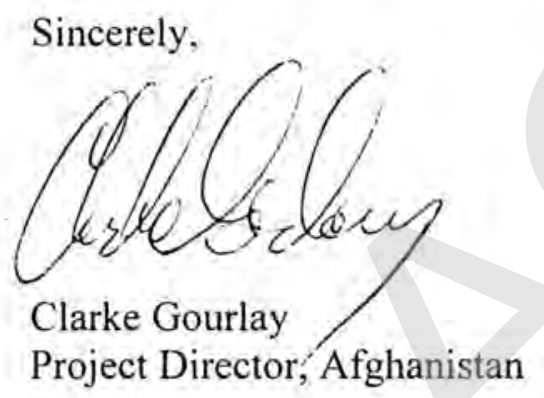

cc-DFID (UK), ECHO (EU), ? (Dutch), ? (Swiss), UNDP-RCO Kabul, ACBAR Kabul \& Peshawar 
1 July 1998

Michael Keating

Strategic Planner, UNOCHA

Islamabad

Dear Mr. Keating,

Enclosed you will find a copy of the paper Common Programming Initiative, Critique, Dangers and Opportunities for Afghan NGOs. This paper was prepared by our Technical Advisor, Don Sauer, after his participation in a preliminary meeting at UNOCHA offices in Kabul regarding Common Programming on 8 June, 1998.

We hope you will find it a useful addition to the discussions and thinking surrounding the Common Programming Initiative as it is implemented over the next few months.

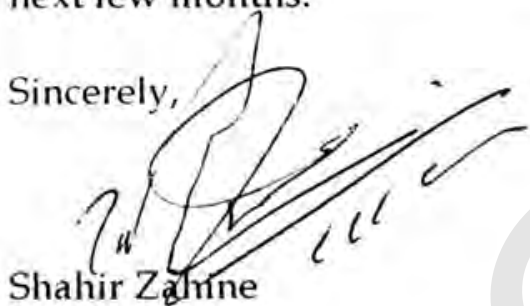

Director, DHSA

\section{Main Otfice:}

H\#95, street 6, N3,Phase 4,

Hayatabad,Peshawar PAKISTAN

$0+92 \cdot 91 \cdot 814401 / 817387$

Fax:+92-91-818203

Email:lapis @ pes.comsats.net.pk

$\begin{array}{ll}\text { Regional Otfice: } & \text { Kabul Field office: } \\ \text { Bamyan Bazar } & \text { Ansari Watt } \\ \text { Bamyan City } & \text { Shahrr- } \theta-\text { Naw } \\ \text { Bamyan } & \text { Kabul City } \\ \text { Afghanistan } & \text { Alghanistan } \\ & 30851\end{array}$

Ghazni Field office:

Qala-e-Mirak

Ghazni City

Bamyan Field office:

Bamyan Bazar

Bamyan City

Alghanistan

Afghanistan
Balkh Field oftice: Kocha-é-Siagard, east of Mazar-e-Sharif City Balkh Afghanistan O3029 


\section{Common Programming Initiative \\ Critique, Dangers and Opportunities for Afghan NGOs \\ by Don Sauer, Technical Advisor \\ 20 June 1998}

\section{Purposes and Authorship}

This paper is primarily aimed at the Directors of the Afghan NGOs (ANGOs) for whom I serve as a technical advisor. Its purpose is to highlight aspects of the Common Programming Initiative. It is my belief that this new approach to funding humanitarian efforts in Afghanistan will, to the extent it is actually implemented, have a profound effect on how and for what purposes relief, rehabilitation and development funds flow into Afghanistan. This paper will also be shared with interested professionals in emergency relief and long term development with whom I have personal contact. It should be understood by any reader of this paper that the views expressed are mine alone and do not constitute an official policy or view of any agency or organization. Although these views have been influenced by the relevant documents and numerous conversations, primarily in the ANGO community, no other individual or agency should be held liable for anything included here.

\section{Motivations for the Common Programming Initiative}

In January of 1997 the UN, at the urging of the Afghan Support Group of donor governments, convened an International Forum on Assistance to Afghanistan in Ashgabad, Turkmenistan. The purpose of this gathering was to improve and reform UN response to complex political emergencies and to use Afghanistan as a test case. It appears there are two main reasons for such an attempt. First, in a global context, the donor governments have lost patience with $\mathrm{UN}$ inefficiencies and lack of coherent and coordinated responses to these chronic emergencies. They want the UN to become more efficient and effective in these situations as the price of continued support for UN leadership in such events. Second, in a specifically Afghan context, the donor governments have felt the heavy burden of continued financial support of UN and other development entities where there is little effective coordination or coherent planning. After decades of support and millions of dollars worth of input Afghanistan still suffers a high level of poverty and ongoing hostility. The donors are looking for a better way:

The document which serves as the primary source of the Common Programming Initiative (CPI) was drafted in a collaborative effort with representatives of the World Bank, UNDP, UNHCR, DACAAR (the Afghan operation of DANIDA) and perhaps another International NGO (INGO). Two of the five participants are Afghans who work with these entities. The document is titled Making a reality of Principled Common Programming dated 24 April 1998 at Islamabad. It serves as the basis for the discussions leading up to implementation of the CPI which is scheduled to begin with the UN Combined Appeal in late 1998 for the 1999 funding cycle.

\section{Common Programming - the Concept}

The stated purpose of the CPI is to introduce a more coherent, coordinated and demand driven element into the funding decision making processes. The Basic Elements of the CPI are:

- Projects selected for funding will be related to specific broad program initiatives.

- Prioritization of programs will be determined by research and analysis documenting the expressed needs of all categories of beneficiaries.

- Programs will embody agreed principles and operational norms.

- Priorities will be determined at the regional and national levels. 
The needs and desires of the beneficiary population are considered to be of the highest priority. These needs, documented by needs assessment and analysis, will be prioritized in keeping with the mandates and objectives of the donor and UN agencies. The donors will then commit to funding programs made up of individual projects which will be coordinated by Regional Coordinating Bodies (RCB) and, at the national level, by an Afghan Programming Board (APB). The makeup and purposes of these bodies will be discussed below. The primary idea is that such integrated programming will provide a better quality of service to the population in a more comprehensive and efficient manner.

Coordination is a worthy goal but the question remains how to make such coordination work in the Afghan situation. There are currently numerous coordinating bodies functioning in the Aid Community. ACBAR, ANCB and ICC all currently make attempts to provide coordination services at a national level. ACBAR has regional offices and ad hoc regional coordinating efforts have been mounted among NGOs working in various regions. A simple glance at this alphabet soup will show that there is competition among the various coordination bodies. To date no coordinating body has had the kind of impact and standing necessary to organize the various capacities available and direct project development down particularly useful avenues. It is difficult to imagine that another layer of coordination effort will be more successful than past efforts. The only thing which makes the CPI seem more likely is the apparently intense desire on the part of the donor community to see this happen. Since they have the money, something is likely to happen in this regard. What it might be is very inuch an open question at the present time.

\section{Regional Coordinating Bodies (RCB)}

The UN currently has high ranking officials serving as Regional Coordinating Officers (RCO). Their function, I gather, is to coordinate the activities of UN agencies active in their region and to interact with NGOs cooperating as partners with UNOs in the region. Under the CPI these activities would be subsumed under the RCBs and the RCO would serve as the facilitator of these bodies. The RCBs would be composed of two main groups. NGOs would provide representatives from among their ranks and all UN agencies would have a seat on this body. The RCB would have three main functions. First, they would prioritize and organize projects under the broad programmatic guidelines established at both the regional and national levels. Second, they would provide a range of common services, taken to mean primarily communications and transport, to support the work and activities of organizations active in their region. Third, the RCB would serve as the primary contact point between the Aid Community and the Presumptive Governmental Authorities.

There appear to be two main problems with the makeup of the RCB. First, all UN agencies would have a seat on the RCB as opposed to NGOs which would have to devise a method for choosing a set of representatives. Second, there is no distinction made between ANGOs and INGOs.

Since this is a UN initiative, even if under duress from donor countries, it may be the price of UN agencies agreement that they all have seats on this board. However, it appears to me that this arrangement gives an inordinate amount of power to UN agencies in the decision making process, especially in light of the fact that it is UN inefficiency and lack of concrete results which are two of the prime motivating factors for creating this initiative in the first place. It also gives the UN agencies an admirable vantage point from which to create mischief or to engage in foot dragging turf battles at the expense of efficient programming.

The failure to make any real distinction between ANGOs and INGOs is another element which is disturbing. At least 5 definite categories of ANGOs can be listed. Each category has its own set of motivations, concerns and priorities. An effort to coordinate and choose representation from among the ANGOs would be a very difficult and time consuming process in and of itself. Although $I$ have much less direct knowledge and information about INGOs it appears likely to me that a variety of distinctions 
could be made among them as well. The off hand suggestion that "the NGOs" determine the best way to provide representation to the RCB seems naive at best. It seems desirable to make some distinction between ANGOs and INGOs with some assured representation from ANGOs on the RCB.

The RCB would function as a de facto Ministry of Planning for the region. It is difficult to understand how the RCB could claim legitimacy and standing if they do not include representation from the Ministry of Planning of the local governments, whether such a government is officially recognized or not. The Taliban government is currently recognized by only two countries, Pakistan and Saudi Arabia. Perhaps this gives the UN and the donor countries the feeling that they have no need to consider the concerns and priorities of the government in these issues. However, the fact remains that the Taliban authorities are in actual physical possession of over $60 \%$ of the territory of Afghanistan and control all the major cities with the exception of Mazar-i-Sharif. If their wishes are ignored or they are not consulted in the planning and implementation of government-like services to the population they will almost certainly be highly resistant. If the government ends up being highly resistant they may feel less inclined to confront UN bodies or donor countries directly than to take out their frustrations on the actual implementers of the projects and programs in isolated field situations. ANGOs are particularly vulnerable in this regard because they cannot easily leave the situation. Unless some accommodation can be found with the authorities or unless the most vulnerable implementers can be brought under some kind of UN umbrella of protection it seems likely that implementers in the field will face harassment, hostility and finally an inability to work.

Under the CPI the RCB would be the primary contact between the Aid Community and the local authorities. Individual NGOs, whether Afghan or International, would be expected to acquiesce in the decisions and directions of the RCB regardless of the contacts and relationships they had built up over time. The key issue in this regard, it seems to me, is whether or not the RCBs can command the kind of respect and authority within the Aid Community which will give them the power to treat effectively with the local authorities. It is true that in some cases coordinating bodies established at the regional level have experienced success by presenting a united front to the local authorities on questions of legitimacy and conflicts. Where this has worked it appears to be a result of a high degree of coopcration among the agencies coordinating their activities and a deep level of integration into the community on the part of the agencies. With this deep integration into the community pressure can be brought to bear on the authorities by the population separate from the Aid Community. If the RCB cannot demonstrate reliably that they are able both to accommodate local authorities and to bring popular pressure to bear on the authorities it is likely they will be ineffective.

There are some specific concerns relating to the geographical makeup of the regions which should be considered. An eastern region consisting of Nangrahar, Laghman, Paktia, Paktika and Kunar Provinces based on Jalalabad may seem to make sense based on a cursory glance at the map. However, the realities of transportation services would seem to lead in another direction. Paktia Province based on Gardez and Khost is much more accessible by ground transportation from Kabul than it is from Jalalabad. I don't know this for sure but I would guess that telecommunication services from Kabul are much more reliable from Kabul to Gardez/Khost than from Jalalabad to Gardez/Khost. Paktika Province based on Sharan is about equally accessible from Gardez and from Ghazni. There are no airports in Paktika Province. The bulk of Paktika Province is to the south of Sharan also so it appears to make more sense to place Paktika Province in the southern region.

Kunduz city at least and probably most of Kunduz Province is essentially an encircled enclave of Taliban control. Geographically it fits in the north but it is difficult to understand how an RCB based in Mazar would be able to do its work in Kunduz. The hostility between the controlling groups would seem to render transport and communication difficult if not impossible between Kunduz and Mazar. I have no suggestions for alternatives but this looks like it would become a difficult administrative 
situation as long as the current status prevails. Of course, the UN does not currently operate in the north anyway because of security concerns so maybe this is a moot point.

The provision of common services, notably communications and transport, will be an important element of RCB support of program activities within the region. The CPI document anticipates establishment of such services for use by entities operating in the region on a cost recovery basis. While this may be of significant assistance to well heeled INGOs and some ANGOs with more stable funding bases it will effectively shut out smaller, less developed ANGOs thus widening the gap between the haves and the havenots in the Aid Community. If the CPI is truly concerned with building capacity among Afghans some mechanism should be found to extend these services to the less affluent members of the Aid Community to enhance their opportunities for organizational development.

\section{Afghan Programming Board (APB)}

The APB is to be made up of the Afghanistan Support Group of donors, all UN agencies and representatives chosen by "the NGOs." My concerns about the makeup of this body are similar to the concerns raised about the RCB. I have no problem with the participation of the Afghanistan Suppurt Group of donors. They are, after all, providing the bulk of the money and it is encouraging to see that they have the interest and willingness to send delegates to participate in the discussions regarding development and rehabilitation initiatives in Afghanistan. Including all UN agencies on the APB seems to me to offer the same opportunities for mischief and turf battles that exist in the RCB and expanding these opportunities to a national level. The naïve assumption that "the NGOs" will be able to devise a truly representative delegation which will have the confidence and support of its constituency seems unlikely. And again there is no role for the national authorities, presumptive or otherwise. They are to be dealt with on a local basis by the RCB and are expected simply to accept the decisions made about the country which they rule with no opportunity for a role in the decision making process.

This issue of sovereinty seems even more troublesome at the national level. On 24 May 1998, less than one month ago, the UN and the Taliban authorities in Kabul signed a Memorandum of Understanding which is designed to allow the UN to again begin work in Taliban controlled areas. I do not have a copy of this document but I have scanned it briefly. One of the articles indicates that the UN will not usurp the authority, the sovereignty, of the Taliban authorities. This seems to me to be in direct conflict with the thrust of the CPI which direct the delivery of government-like services throughout Afghanistan.

Although the current authorities are recognized by only two countries they do in fact control a major portion of the countryside. Their ability to confront the UN authorities directly is limited but not completely absent as the UN has learned to its chagrin. However, it seems much more likely that the authorities would allow their displeasure to become known by arbitrary and hostile actions against individual implementing agencies in the field, both International and Afghan. Of course, the ANGOs are much more vulnerable in this situation because they have nowhere to go. They are inextricably tied to Afghanistan. INGOs can move on to more cooperative pastures if things become too unreasonable in Afghanistan.

Paula Newberg, I don't know who she is; I presume she has a position in the UN system, has written a detailed paper regarding Monitoring and Evaluation. She indicates that the most important element of a system-wide Monitoring and Evaluation system is to strengthen existing capabilities. The UN agencies all have Monitoring and Evaluation standards as do most of the established NGOs, both Afghan and International. A critical effort in the implementation of the CPI would be to standardize these methods and to create a set of guidelines that would be accepted and used throughout the Aid Community in Afghanistan. This strikes me as a massive effort and one which will again highlight the differences among the donors, the UN agencies, the INGOs and the ANGOs. These differences will arise as a 
result of differing motivations, goals and objectives under which the various categories of aid providers operate. At the present time it is difficult to imagine that the various methods and standards can be brought under one umbrella of agreement.

Monitoring and Evaluation in terms of impact assessment is the topic of Ms. Newberg s paper. She leaves the issue of financial audits aside as being different in kind and purpose. This seems appropriate to me. Clearly there is a need for ongoing financial accountability and the transparency of financial actions. But this is an altogether different thing from assessing the impact of programs in terms of their long term impact.

The biggest problem, it seems to me, is that there is no agreed upon view of what Afghanistan would look like if programming were performed at optimal levels. If we do not know what we are aiming for it is difficult to understand how we can measure our progress toward the goal. It seems clear to me that there are distinct differences among the various players about the relative importance of various issues. The gender issue is a good case in point. Donors and UN agencies have placed a high priority on improving the lot of women in this society. It is my impression that the leadership of most ANGOs is in sympathy with this goal. However, it also seems clear to me that this issue does not have the same urgency for ANGOs as it does for other players. They have made this a part of their programming and proposals because of external pressure in the form of funding to do so. The ANGOs would be more inclined to provide a range of services which serve the whole community, including women and children, to the greatest extent possible. This is especially true when the ANGOs are faced on a daily basis by the hostility of the local authorities to services and projects directed toward women. It is good in at least one way that this external pressure has existed because it has caused a higher level of awareness and effort to exist among ANGOs.

A similar discrepancy exists in the high priority given to the eradication of poppy culture in Afghanistan. This reveals a certain hypocrisy on the part of the external forces. The supply would not exist if there was not a huge demand for it. Until the affluent nations can do something serious about the demand for poppy and its products there will be a supply, whether from Afghanistan or from somewhere else. To date there has been no serious program to divert production from poppy to some other equally lucrative and less malign crop by the UN or anyone else. The UN has apparently contented itself with requiring that NGOs certify that the things they do will not increase or assist the cultivation of poppy. That is a weak approach at best.

The cultivation of poppy and cannabis in Afghanistan has a long history. It was frankly not much of a problem for anybody, including Afghans, as long as the poppy was used as opium with mild medicinal and recreational purposes. With the advent of the war and the ensuing destruction of community norms and standards opium began to be refined into morphine and heroin as a means of financial support for the resistance and later just to make large amounts of money. That could never have happened without a major market worldwide for these products. The same can be said of cannabis although it is less important worldwide because of its bulk and its resistance to refinement into more powerful drugs.

The result is that everybody in the system gives lip service to the importance of reducing the drug flow from Afghanistan but nobody is doing anything substantive about it. The donors tell everybody to make it a high priority but they have done little if anything to limit the demand in their own countries. The UN forces everyone working with them to agree to make it a priority but UNDCP has little chance to do much in the face of indifference on all sides of them. The Afghan authorities talk of reducing the flow but they receive taxes from it and have no alternative to offer farmers. Afghans generally see it as somebody else's problem and not very important in their own lives.

These are two important examples of discrepancies of approach and priority which must be dealt with directly if any kind of Monitoring and Evaluation program is to have the broad support of all the 
players involved. A well defined and mutually agreed upon set of Monitoring and Evaluation standards will be a critical requirement if the $\mathrm{CPI}$ is to have any real hope of positive outcomes.

\section{Dangers for ANGOs}

The local authorities, called the Presumptive Authorities because the Taliban and other groups enjoy almost no international recognition, have almost no role to play in the determination of priorities and programs which the APB and the RCB would establish and seek to implement. This appears to me to be a circumstance which would remove sovereignty or governmental authority from the authorities in place. Although the local authorities have shown the willingness and ability on occasion to confront the UN and other external forces directly, it seems much more likely that they would make their concerns known by hostile or restrictive actions against NGOs operating in the field and trying to do the work which they had agreed to undertake under the CPI. While INGOs might experience some difficulties and trouble with implementation they are not completely bound to Afghanistan. ANGOs do not have this luxury. The whole purpose of their existence is the Afghan crisis and ANGOs could be forced to cease operations or be severely limited if they are seen as a part of a conspiracy to take over Afghan authority or sovereignty. It will be important to deal with this issue directly as the implementation of the CPI proceeds or it will almost certainly fail. And it could take many ANGOs down to failure with it in these circumstances.

Traditionally, ANGOs have operated from project to project with little chance to build organizational capacity or to sustain themselves over time. This is due in large part to the resistance of donors and UN agencies to the idea of ongoing or secure funding for ANGOs. This has made and continues to make it very difficult for ANGOs to develop the kind of organizational strength necessary to survive the ups and downs of funding cycles. Often ANGOs have been given large operational and capital expenditure budgets but have been refused money to put necessary systems in place to deal with these larger scale operations. Unless some mechanism can be established to provide money, services and training to ANGOs on a secure and ongoing basis it is difficult to understand how sustainable capacity is to be built in Afghanistan.

The CPI anticipates the creation of a set of common services, primarily transport and communication facilities, which will be available for use by UN agencies and NGOs on a cost recovery basis. This is an admirable goal in theory but the cost recovery element will limit its effectiveness in many cases. ANGOs with difficult cash flow situations will find it difficult or impossible to make use of such facilities. Unless some agreement can be established that will allow use of these facilities with morc freedom it will widen the gap between the haves and the havenots in the Aid Community.

A common set of Evaluation and Monitoring guidelines and practices will be a key element in the success of the CPI. For the reasons outlined above this will be a major task. Unless a reasonable and agreed upon set of standards and guidelines can be established with the consent of all the various elements of the Aid Community there will be no solid information available as a result of Evaluation and Monitoring activities. ANGOs should make every effort to assure that they have a voice that is heard in the construction of these Evaluation and Monitoring guidelines as they are developed.

Economically motivated organizations which have registered themselves as NGOs with the Taliban Ministry of Planning in Kabul have a definite place in the reconstruction and rehabilitation of Afghanistan. They provide employment and often have a high degree of technical skill available to them. However, they should not be confused with the humanitarian motivated NGOs who seek to do longer term development work as well as providing technical expertise for reconstruction and rehabilitation. Because of the donor and UN disdain for economically motivated businesses these groups call themselves NGOs in order to attract possible funding. They tend to exaggerate their capabilities in areas for which they have little experience or qualification. There needs to be an 
understanding of the importance of these businesses on the part of the Aid Community and encouragement of them in situations for which they are best suited, mostly construction projects. There also needs to be clear distinction between these organizations and the humanitarian organizations.

Over the years an attitude of disdain and distrust has evolved among many donors, UN agencies and INGOs for the trustworthiness and sincerity of ANGOs, not to mention the Afghan people as a whole. If this $\mathrm{CPI}$ is left in the hands of people from the outside it will only strengthen and deepen this sense of distrust various individuals and agencies feel for the Afghan agencies and people. ANGOs must make every effort to present themselves and their concerns with a strong and professional attitude. ANGOs must take the initiative and insist on being treated as equal partners in this venture. Without this assumption of equality it will be impossible for sustainable capacity to be built in Afghanistan and among the Afghan people.

Another major danger to ANGOs if they allow themselves to become mere extensions of INGOs and UNOs will be the creation of distance from the communities they are pledged to serve. If ANGOs are seen as errand boys (or girls) for the external agencies they will lose credibility and contact in their communities. This will limit their effectiveness at the grass roots level. Similarly, ANGOs who simply follow the lead of the external agencies will be the most obvious targets for the local authorities if and when they wish to embarrass the external agencies. Those ANGOs who are able to cooperate with the CPI while maintaining integrity and independence will be in a much better position relative to the authorities and to the communities they serve.

\section{Opportunities for $A N G O S$}

While much has been said about the dangers and concerns facing ANGOs in this paper, the fact remains that there are some real opportunities in the CPI. One of the most important is that there appears to be an opening to do some real capacity building among ANGOs and in the Afghan situation overall. The donors and the UN have begun to realize that failure to build lasting capacities among the Afghan people and Afghan organizations prevent any real sustainability of efforts. The CPI opens the door to a much broader range of capacity building efforts than has been the case in the past. While training is indeed a part of any good capacity building program, it seems clear that all kinds of capacities need to be built in the economy as a whole as well as within ANGOs. Therefore, it seems to be an excellent time to think seriously about possible capacity building and organizational development ideas which can be used as the basis for proposals over the next years.

It seems desirable to move Afghan development operations inside Afghanistan at the earliest practical date. The reasons for having operational headquarters outside Afghanistan include a lack of secure sites from which to conduct operations, lack of reliable communications functions, difficulty of transportation due to awful roads, numerous frontline type situations and no smoothly functioning banking systems. The CPI seems to offer some opportunities, over time, to alleviate some of these with the result that it might be possible to begin a serious move to bring Aid Community headquarters into Afghanistan itself rather than in Peshawar or Islamabad. If the ANGOs led this movement it would give them credibility and a position of leadership in this regard. The focus on the provision of common services as well as the growing difficulties of conducting operations from a Pakistan base might provide the push needed to get such a return exodus underway.

If ANGOs are to have anything other than a secondary role in the CPI it will require them to develop the skills and mechanisms among themselves to make the best use of resources available and to cooperate with each other. The ability to coordinate activities and to share resources for the good of the people they are pledged to serve will be critical. If such skills and mechanisms can be developed in such a way that they are consistent with Afghan tradition and culture these skills and mechanisms will be highly useful long after the external entities have gone on to the next crisis. 
In the past ANGOs have had little opportunity to influence the goals and priorities of external donors, UNOs and INGOs on behalf of the Afghan people. Lacking the ability to provide such input in a manner which makes a positive impression on the external agencies ANGOs and the Afghan people have been left to make do with programs which lack imagination and cultural sensitivity in many cases. With the emphasis on a "demand driven" approach to funding and programming in the CPI, ANGOs have the opportunity to take the intellectual initiative in programming. Failure to do so will leave ANGOs in the current position of looking abroad for the leadership necessary for the emergence of a peaceful and more prosperous Afghanistan. Leadership in this case should be Afghan.

In addition to the opportunity to address the priorities of external agencies, the CPI may present opportunities for the ANGOs to influence the priorities of the current authorities. If ANGOs are seen to be full and equal partners in a comprehensive set of programs with external funders they will have a higher ability to influence the authorities priorities and programs. In many cases ANGOs have a long history with the local authorities and are in the best position to influence them to accept, incrementally, some changes seen as necessary. This is especially true of issues like gender. While there are many dangers for ANGOs in their relations with the local authorities, it seems clear that the more they can be seen as strong and independent entities the more influential they will be with local authorities. This implies a strong presence in the communities they serve because the local population which is in favor of the ANGO serving its community can bring some pressure to bear on the local authorities. This enhances ANGO credibility and bargaining position relative to the authorities.

\section{Summary}

This paper has been an attempt to highlight some of the issues relevant to ANGOs as they are confronted with a changed pattern for the funds and assistance flowing into Afghanistan from the outside. I wish to restate here that the views expressed here are mine alone although they owe much to conversation and thoughts expressed by my colleagues in the ANGO community, However, no other individual or agency bears any responsibility for these views.

The CPI is an admirable idea in theory. Coordinate the flow of resources into the Afghan situation so as to improve the overall programming coherence and effectiveness. However, there are many details still to be worked out and it will be important for the ANGOs to take a leading role in determining how these things will actually be implemented. I hope this paper will prove useful to those Afghans and others struggling with these problems and trying to make the CPI a worthwhile innovation in the delivery of development services. 


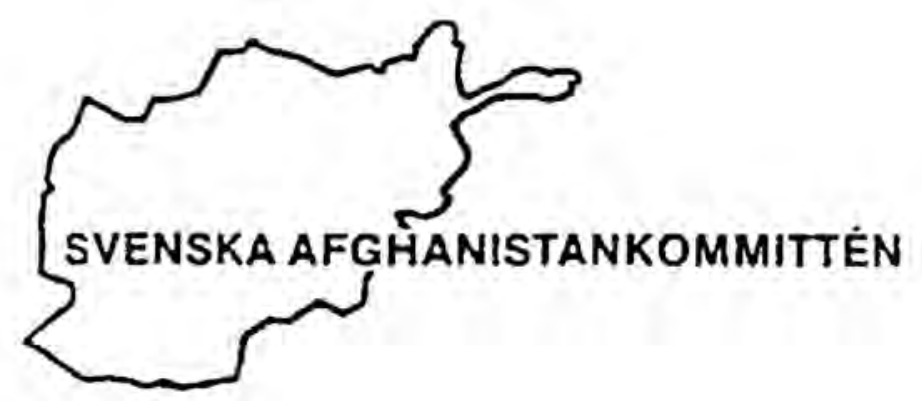

\author{
Mr. Michael Keating \\ UNOCHA \\ Islamabad
}

Dear Mr. Keating,

During its June 6, 1998 session, the Executive Board of the Swedish Committee for Afghanistan discussed the question of increased and improved cooperation between agencies working for relief, reconstruction and development of Afghanistan. In this connection, the Board reviewed related documents, "Strategic Framework" and "Making a reality of Principled Common Programming". Following these deliberations, the Committee would like to make the following comments:

1. The Swedish Committee for Afghanistan strongly supports the efforts to improve cooperation and coordination among agencies participating in the international assistance effort in Afghanistan.

2. In such effort it is, in the Committees opinion, natural to expect the United Nations and its family of organisations to play a lead role. This role reflects the fact that some of the fundamental principles guiding the provision of international assistance, e.g. respect for human rights, the rights of women and children's rights, are embedded in the United Nations Charter as well as in various international treaties, conventions and resolutions sponsored by the United Nations.

The modalities of common programming will no doubt have to be worked out at the field level between the parties concerned. In order to translate the broad principles or programme collaboration and coordination into practical implementation, it will be necessary to give the process sufficient time and to go about it with sufficient flexibility. The task is complex and the challenge is great; too much haste or a too formal approach should be avoided. It might be necessary, for example, to aim at something less than a full-range, completed Consolidated Appeal for 1999, because of the time factor. Meanwhile, experience will be gathered in working together, a regional organisational framework will be in place and a more complete document could be produced for the year 2000 (for completion late 1999).

\begin{tabular}{llr}
\hline Swedish Committec for Afghanistan & Pg 64 23 90-9 & Tel. 08-66085 50 \\
Sturegatan 16 & Bank: Handelsbanken acc, 104577 762 & Fax: 08-660 8548 \\
11436 STOCKHOLM; Sweden & ORG.NR 802010-48 50 & c-mail: sca-sak@algonet.sc
\end{tabular}


4. The establishment of an operational machinery for coordination and common programming will require additional resources to be put at the disposal of the UN system in the field, for the Afghan Programme Board (APB) as well as the Regional Coordination Bodies (R.C.B.). This applies in particular for completion of such qualified tasks which are being proposed in "Principled Common Programming" e.g. data collection, information gathering, needs assessments, planning, monitoring and evaluation, standard setting, training etc. In view of the limitations faced by NGOs with regard to funds and available expertise, it would also be important to make sure that additional resources be provided to NGOs, for the purpose of allowing them to actively and constructively contribute to the common programming exercise.

5. Finally, the Swedish Committee sees the two documents under review as expressions of a wish among the participating organisations to join hands in a joint endeavour to find ways and means of working closer together for the welfare of the people of Afghanistan. At the same time, the Committee is aware that each of the agencies entering into the proposed collaborative arrangements under $\mathrm{UN}$ auspices will retain its own legal and administrative structure, its own policies and organisational priorities as well as its own governance.

The Committees Country Director, Mr. Anders Fänge, has already made his own comments on the proposals. We agree in principle with his comments and enclose a copy of them for your information and record.

Stockholm the $26^{\text {th }}$ of June, 1998

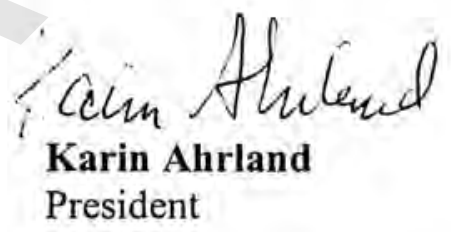

cc. David Wiking, Sida, Stockholm 


\section{Supplement II}

Responses to the 'Making a Reality of Principled Common Programming' document

Islamabad, 28 July 1998 


\section{N T R O D U C T I O N}

\section{Dear Colleagues}

Please find enclosed a further set of reactions to the 'Making a Reality of Principled Common Programming' document.

This volume is the third we have sent you. The first was distributed in early July; and the second, entitled 'Supplement', on July $17^{\text {th }}$.

This set includes reactions from Habitat, IAM as well as a copy of the recent Central Highlands/Hazarajat region Common Programming Workshop.

It also includes a study written by Peter Marsden of the British Agencies Afghanistan Group (BAAG) on how best NGOs can engage with the proposed common programming mechanism. This report was prepared with financial assistance from the Commission of the European Communities. The views expressed are those of the NGO, and do not represent any official view of the Commission.

Thank you once again for your cooperation and interest,

Michael Keating

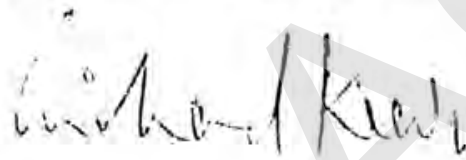

On behalf of

Alfredo Witschi-Cestari

UN Coordinator, Humanitarian and Development Activities in Afghanistan 


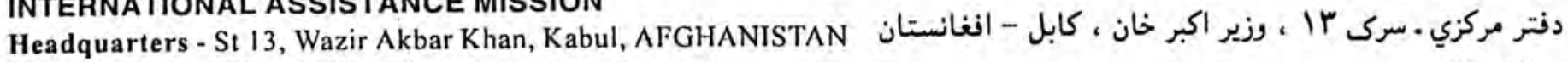

To Michael Keating, UNDP

cc Jolyon Leslie, RCO Kabul

cc ACBAR

cc Selected IAM funding partners

28 June 1998

\section{Common Programming - IAM response}

Dear Mr Keating,

Please find enclosed IAM's written response to the proposals for Common Programming. May we take this opportunity to express our thanks for the efforts you have made in carrying this process forward, and in particular for the opportunities you have given for NGO input.

Good luck with the revised document!

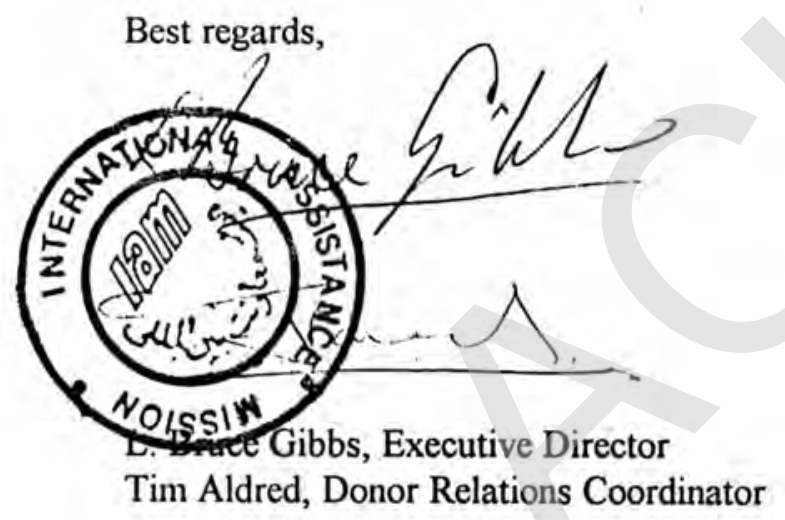




\section{RESPONSE TO PROPOSALS FOR INTERAGENCY COMMON PROGRAMMING FROM INTERNATIONAL ASSISTANCE MISSION (IAM)}

JUNE 1998

\section{CONTACT DETAILS}

Mailing address: Box 1167, Peshawar, Pakistan, Fax+9291 842634, email iamhq@maf.org International Headquarters Office: Street 13, Wazir Akbar Khan, Kabul, Afghanistan Executive Director: Mr Bruce Gibbs

\section{ABOUT THE IAM}

The IAM has served in Afghanistan for over 32 years. We operate in long term development activities: Health, Community/Economic Development, Education, Rehabilitation; Also in Relief/Rehabilitation. International staff from 18 countries serve with the IAM in Afghanistan.

\section{SUMMARY OF RESPONSE TO COMMON PROGRAMMING}

The IAM wishes to be constructively involved ongoing discussions regarding Common Programming. We believe Common Programming to be potentially very beneficial for the overall provision of aid to the people of Afghanistan. Common Programming can reduce interagency overlap, competition and serious conflicts of priorities. Common Programming can help different agencies work together in a coordinated manner for the benefit of the Afghan people. However, we do retain specific concerns about the proposals for the practical implementation of CP currently put forward. These are expressed in detail in the comments which follow.

\subsection{ROLE OF THE REGIONAL COORDINATION BODIES (RCB) AND AFGHANISTAN PROGRAMMING BOARD (APB).}

3.1.1 These bodies should be policy focused, considering the broader policy issues affecting the assistance community. Technical/operational questions should be addressed primarily through sectoral working groups. The APB/RCBs should facilitate and enable, rather than dictate. The concept of the APB/RCBs vetting all project proposals would seem to be unworkable. A more constructive approach would be for the APB/RCBs to agree broad principles/priorities which would then inform both implementing agency project planning processes and donor project selection criteria.

3.1.2 The APB/RCBs should consider policy on a longer term basis. This mandate has been criticised as offering insufficient flexibility and adaptability to changing circumstances. However, developing political problems (eg between agencies and the authorities) do not exist in a vaccuum, but are developments in a continuing process, and the most appropriate responses by the assistance community are ones which sit within a longer term framework.

The point of an overall coordinating body is that it could develop these long term strategies for relating to changing political realities, and move the assistance community away from reactive short term responses. Indeed, this perceived need has been one of the driving influences behind the creation of CP. In particular, policy relating to agency response to human rights issues should strive to keep a long term view.

This long term APB/RCB vision, if carefully formulated, would also not restrict a quick agency response to urgent humanitarian disasters, neither would it restrict the ability of agencies to respond to new legislation/new operational difficulties, but would rather enable responses to such difficulties to be made in a more consistent manner over the long term. 
3.1.3 Where sectoral groups already exist, these should be encouraged and supported, not duplicated. There are already groups in many sectors which are functioning well. New sectoral groups should only be initiated if they do not currently exist.

3.1.4 There should be fair representation of all stakeholder groups, including international and national NGOs on the RCBs and APB. There should be a transparent process for the election of representatives to these bodies. The APB and RCBs should continue to consider and promote ways to involve ordinary Afghan people in their work, given the stated long term vision of handing over $\mathrm{CP}$ to Afghan control in the future. It would for example be both feasible and very beneficial to the process to involve local community groups in some way in discussing needs and priorities for $\mathrm{CP}$.

3.1.5 The expatriate community within Afghanistan tends to turn over quickly. The $\mathrm{RCB} / \mathrm{APB}$ should be composed of members who will personally have a long term presence. If not, these bodies could suffer badly from discontinuity and 'reinvention of the wheel' every 6 months. Good documentation would also be key.

3.1.6 The RCBs should have sensible contingency plans for its continuing work during poor security situations. In the event of poor security, RCBs should not automatically start meeting away from their region, making decisions on behalf of agencies still working on location.

3.1.7 The creation of the RCBs and APB may raise questions for current Agency Coordination bodies. There needs to be careful consideration of how such existing bodies will work with the new structure.

3.1.8 Good monitoring, evaluation and analysis is key to the success of CP.

3.1.9 The RCB/APB must not become 'the UN in all but name' - ie UN led, as some donors are proposing. If the RCB/APB does not hold to this, NGOs will lose faith in $\mathrm{CP}$.

3.1.10 The proposal to submit all agency project proposals through the Consolidated Appeal is flawed. This is an unwelcome degree of UN control until such time as the Consolidated Appeal is run cooperatively between NGOs and the UPK

\subsection{RISKS}

3.2.1 Bureaucracy and unnecessary extra work

3.2.2 Poor representation of the views of different stakeholder groups on the $\mathrm{APB} / \mathrm{RCBs}$ leading to poor analysis and decision making.

3.2.3 The CP should not become dominated by any one agency or group of linked agencies.

\subsection{POSITIVE ASPECTS}

3.3.1 The proposed planning cycle for Common Programming sits easily with IAM's own annual planning cycle.

3.3.2 The currently stated priorities of the Strategic Framework and Assistance Strategy for Afghanistan are in broad agreement with those of the IAM.

\subsection{OTHER COMMENTS}

3.4.1 Proposed training for capacity development is obviously good, but this should be focused on personuel who will have a long term presence in Afghanistan, especially Afghan nationals. This is especially important considering the high turnover of international staff within Afghanistan.

3.4.2 Our understanding is the committment to $\mathrm{CP}$ remains voluntary, and agency autonomy is not compromised. We will as an independent NGO then be tempted to lose faith in $\mathrm{CP}$ if we sense that $\mathrm{CP}$ is not being regarded as an equal 
partnership of NGOs, UN, and Donors, where the views of all are respected in decision making. However, the success of $\mathrm{CP}$ will depend upon a definite commitment of all involved to constructive involvement with CP and the IAM is therefore committed to doing as much as possible to make the process work.

\section{ABBREVIATIONS USED \\ IAM International Assistance Mission \\ APB Afghanistan Programming Board \\ RCB Regional Coordination Board \\ $\mathrm{CP}$ Common Programming \\ NGO Non-Governmental Organisation}

This version drafted in Kabul on 22 June 1998 by Tim Aldred, LAM Donor Relations Coordinator 


\section{战造}

United Nations Centre for Human Settlements (Habitat)

AFGHANISTAN

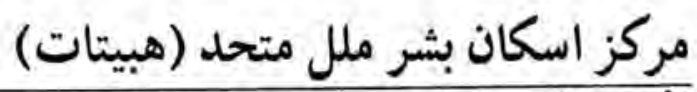

AFG/96/005

Alfredo Witschi Cestari

UN Coordinator

Afghanistan

$15^{\text {1h }}$ June 1998

Dear Alfredo:

\section{Making a Reality of Principled Common Programme}

After discussions with our Programme Officers

Please find set out below our comments, both general and specific, on the yellow book entitled as above. We hope they help you in reviewing the document.

\section{General Comments:}

Key issues, which need discussion and clarification:

I. There is a problem with managing the dynamic/dilemma between working by consensus and the need to give leadership and direction to decide what is compatible or not compatible. Practically speaking this means that the Regional Programming Boards have to have a mechanism for dealing with cross cutting issues and a way to establish priorities in the programme.

II. Related to the above is the need to clarify the principle issues or needs and put them in priority order. Is it creating sustainable livelihoods or providing much higher standards of healthcare? If it is the former should we not redirect resources from the latter? How should we reallocate?

III. When the programme is arrived at (by whatever means) then it should be examined in public (EIP) this procedure sets out clear guidelines for defending the contents of the programme and the projects attached. The EIP is moderated by a chairman and constituted by an independent panel. It examines the issues by sector or theme. In a transparent way it reviews the programme, reexamines the statements made by agencies, NGOs and third parties with the intention of endorsing the programme or making recommendations for change. This would make a quantum change from Agencies just "telling everyone" what their policy and programme is. The examination might take 3 weeks to go through its work. It should work to rules otherwise people might not take it seriously.

IV. The above is important to ensure programmes and therefore, the appeal, is structurally sound, that is cohereni, that projects are attached to agreed 
V. programmes and that dissident voices are heard, their concerns registered and dealt with.

VI. It seems important to us that we deal with the issues of humanitarian assistance versus development. The former approach is in some instances causing problems, which should be discussed. Quick impact projects should be carefully though through especially if they take place in close proximity to those agencies who are utilizing a more developmental approach. Whilst it is extremely difficult to do we should be able to separate out that assistance which is purely 'emergency'.

VII. The Memorandum of Understanding is related to the common programme process in that we have a window of opportunity with regard to Health and Education issues right now. However, recent events in Kabul suggest that perhaps some elements of the Taliban are not committed in reality as much as they are on paper. It seems appropriate that the Common Programming Process could focus on these two issues quickly.

\section{Specific Comments on the Yellow Book:}

1. The need for more "participatory needs assessments" is a little questionable. Let us first review what information is available by sector/theme etc. What happened to the CIET work sponsored by UNICEF? There must be many studies iike this tucked away. If we have more needs assessments then a structured or selective approach to data collection should be set-up. We have referred elsewhere (point 12 below) to the need to put major studies (and perhaps even minor ones) through some sort of vetting process. A strategy for coordinated data collection is long overdue.

2. It is not at all clear that the common programming process will offer a cost efficient mechanism whereby policies and priorities might be agreed. If we claim this, we should be prepared to show how this would be achieved. We suspect there is a contradiction here. On the other hand we claim to the donors that coordination is not cheap (ProMIS, consultants, capacity assessments, training programmes, common services, etc.), and yet then we claim it is more cost efficient.

3. We doubt very much we can agree detailed 'term of engagement' with authorities. We have not done so far and the criticism attracted by the Memorandum of Understanding is a measure of how difficult it is to do so. We should not put too much store in trying to get this right. We have to be fluid, quick on our feet, and rely upon the principles and operating guidelines to dictate how we work with the authorities. Let us not commit ourselves in writing to detailed terms of engagement that we may regret later.

4. Page 6. Para 4. Reference to " see 4.5 below". 4.5 does not exist. 
5. Twice yearly meetings of the RCB is not enough. Perhaps quarterly would be a better idea, plus there should be a mechanism for convening extraordinary meetings.

6. Bamyan does not relate geographically or economically to Kabul. It should have its own separate (not sub)RCB.

7. Establishment of thematic groups mitigates against examining cross cutting issues. Our suggestion would be look closer at integrated upgrading strategies, such as 'shelter' or an 'industrial rehabilitation strategy'. The latter for example allows us to integrate power, telecommunications, water supply, training etc.

8. Logistically speaking, and for parity and transparency, the RCBs should discuss all proposals. This might mean in Kabul, for example, looking at about 700 projects or more a year. In these circumstances, it might be best that we first agree sets of practical guidelines, policies and standards e.g. WATSAN policy guidelines or urban policy guidelines covering a number of sectors. This will ensure that agencies proposals are at least in line with generally agreed policy. First job of the groups, therefore, is to produce agreed guidelines. Alternatively, instead of being copied to all agencies, proposals could be copied into a 'live' file kept in the RCO office for a specified time prior to an RCB meeting. Only controrvasial issues would be raised in the RCB. As a suggestion we should have agreed shelter policy, national agriculture strategy, educational guidelines etc. They may have to be different across the country.

9. ICRC, IFRC needs to participate in coordination meetings if they are to continue involvement in drainage, agriculture, sanitation, income generation etc.

10. We still cannot see how big the RCBs will be. Will it be one agency, one vote? Will there be a right of appeal for agencies aggrieved by decisions. What if the $\mathrm{RCB}$ says a particular agency's projects don't make sense?

\section{Common Services:}

11 Most of what is described is already in place. Some of the NGOs have much better facilities than us. Will they be pooling their services in ACBAR or elsewhere for our benefit? For transfer of cash perhaps we should revitalize the Da Afghanistan Bank and provide a full banking service at UNDP. This is fine for Kabul, but what about elsewhere?

12 Use of ProMIS by any agency ideally should be contingent upon information being made available by the agency to the database. The cost of providing services you described on demand will be enormous. There should be a central Study Fund available for studies that in the opinion of the APB would make a significant contribution to information resources. We have a draft project proposal which is modeled on the World Bank's Social Action Progranmme 
13 information collection methods. The study Fund could be controlled by APB and be directed to undertaking necessary surveys of a large scale.

\section{Functions of the APB:}

13 If we want the APB to agree on national assistance programming priorities, will they be empowered to ask for external audits of programme? How do we know that any particular programme is meeting a priority, whose priority? Will the Monitoring and Evaluation unit carry out special studies to provide the required information? We do not believe that just Afghan NGOs represent Afghan Civil Society. Should not a broader representation be sought? You have admitted this on page 14 Para 7. Who will do the work you mention? Who will act as secretariat for the APB? Will all the board members fit in one room? Are the thematic groups under the APB the same as those of the RCBs or different ones? Do they talk together if they are different bodies?

14 Policy setting and clarification: You mention the " prohibition on engagement in institution building efforts". The APB will realistically need to look closely at our existing work arrangements such as UN and NGO medical agencies with the MOPH or UNDCP with the Taliban Drug Enforcement Commission.

15 Setting programme priorities seems to be an issue. Who takes the lead? There is an apparent inconsistency between expecting the RCBs to define programme priorities yet recognizing that there is a need to establish priorities at the national or pan regional level by the APB. What comes first? Is it an iterative process?

16 Para 5.1 page 14. Your statement is wholly true but the yellow document carefully avoids detailed discussions on how this will be achieved. The statement"....can eventually assume responsibility for it" assumes some kind of "capacity building" of institutions. What sort? There are a dwindling number of technocrats who work for the government authorities- are they to be ignored? We agree with your suggestions for a long-term approach to community organization, but presently there are a great variety of approaches.

17 The involvement of the authorities in the work of the RCBs is a tricky question. If, as you suggest in Para 5.1.2. RCBs engage authorities in their thematic groups or even Boards we undoubtedly raise their expectations as to involvement in the planning and implementation phases. Some would say we have already done this through the Memorandum of Understanding so why should we worry.

'Appropriate parameters' for relations with Authorities can not be dealt with twice a year. It is a moving feast with 'parameters' discussed almost on a daily basis as we react to edicts /dictats and other spontaneous events. We also cannot expect that presumptive authorities will be left out ( a future agenda item) of the RPBs or APBs. There is growing support for solving this issue now. For example, is it up to an RCB to decide whether and how to involve the authorities or is this too important a decision? For example, what if one RCB wants full cooperation and another wants none? 
I hope the above comments assembled by our team in Habitat help your office to revise the document. No doubt our comments are one contribution amongst many but we have taken time to participate and hope they count for something in the final analysis. We take this opportunity to congratulate you and your office for having the stamina to go this far on a task which is far from easy.

UNCHS Afghanistan will continue to play an active role in the development of the Common Programme.

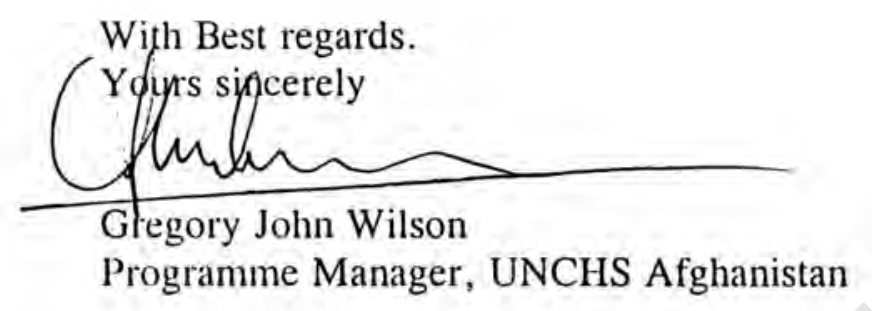

cc. M.Mathema SHSA, UNCHS Fukuoka 


\section{NGOs and the Common Programming Process}

A consideration of the ways in which NGOs operating in Afghanistan can best engage with the Common Programming mechanism

JULY 1998

British Agencies

Afghanistan Group

the refugee council 


\section{INTRODUCTION}

As part of the ongoing efforts of the donor community to achieve greater effectiveness within the UN system, particularly in relation to what are termed "complex emergencies", the UN Secretary-General has established a mechanism known as the Strategic Framework Process. This initiative is seen as crucial to the continuing confidence of donors in the UN system and the UN Secretary-General has determined that Afghanistan shall serve as a test case to explore how such a process night best work in practice.

Discussions on this have evolved to the point where a more refined mechanism, designated "Principlecentred common programming" has been formulated, a draft consultation paper has been produced, and comments on this have been submitted.

The key element of "Principle-centred common programming" is that a structure will be created through which donors, UN agencies, ICRC and NGOs will engage in a joint programming process on the basis of a principled approach. The proposed structure involves the determination of policies, standards and priorities at the national level through the Afghanistan Programming Board and at the regional level through a network of Regional Coordination Bodies. The structure does not, at this stage, include programming for refugrees in Pakistan and Iran, for which UNHCR retains overall responsibility.

The draft document envisages that the APB and the RCBs will exercise a degree of control over the programmes of individual agencies, including the processing of applications for funding through a single mechanism, the Consolidated Appeal. It also proposes that an independent monitoring and evaluation unit be set up.

The "Principle-centred Common Programming" approach raises a number of key issues, notably:

(a) how humanitarian agencies should best implement a principle-centred approach.

(b) whether humanitarian agencies are prepared to allow an external structure to exercise control over their activities and, if so, to what extent, and what role donors should play in any enforcement process.

(c) how NGOs will be represented on the Afghanistan Programming Board and the Regional Coordination bodies and how they will feed information and concerns to their representatives on these bodies.

(d) how humanitarian agencies will, in practice, implement a demand-led approach to programming: by which mechanisms should UN agencies and NGOs engage with village and neighbourhood structures so as to strengthen indigenous capacity?

(e) how humanitarian agencies will, in theory and in practice, engage with presumptive authorities/power holders.

These questions require ongoing debate within the aid community but their effective consideration would benefit from an understanding of what already exists so that the principle-centred common programming process can build on progress already made as well as take account of existing constraints. This is all the more important because of often incorrect assumptions and misconceptions that are held about players within the aid community by other players.

There is a consensus among the key players that, to improve the chances of principle-centred common programming being successful, an analysis would be of value as to the existing mechanisms whereby NGOs communicate with other players and whereby they determine their operating principles and standards. 
This paper will therefore set out to document and analyze the communication mechanisms that exist between NGOs and between NGOs and donors, UN agencies, beneficiaries and presumptive authorities/power holders. It will also look at what processes exist within individual NGOs to determine policies, operating principles and standards and at how these relate to the processes which exist among donors and UN agencies. The paper will, in addition, give some tentative thoughts as to how, based on the findings of the study, NGOs and other assistance actors could most appropriately engage with the principle-centred common programming process.

\section{METHODOLOGY}

For the purpose of this study, a semi-structured questionnaire approach has been used, to interview a crosssection of NGOs so as to include:

(a) NGOs operating on the basis of an integrated community-based approach.

(b) NGOs working to provide health, water supply, sanitation and, where possible, education within urban areas.

(c) NGOs working to provide health, veterinary and education services over large areas for the rural population.

(d) NGOs of different national or regional origins so as to include Afghan, Islamic, European and North American NGOs.

The questionnaire was used with due regard for the different areas of focus of individual agencies and different operating constraints, particularly in relation to principle-centred programming, where some agencies were facing greater challenges than others.

In most cises, it proved possible to spend two to three hours with each agency but, in some cases, time was constrained and it was necessary to focus on those aspects of the agency's communication with others which was of most benefit to the study.

All agencies were asked to what extent their work was of direct benefit to returning refugees or to IDPs. However, some agencies were interviewed which were known to work in areas which were not primary centres for refugee return or had not experienced significant IDP movements, in order to maintain a balance on other counts. The vast majority of agencies interviewed were, nonetheless, providing assistance to returnees or IDPs.

Meetings were also held with the Coordinators of ACBAR, ANCB and ICC. In the case of ANCB, it proved possible to meet representatives of a number of member agencies through two meetings organised. A meeting was, in addition, held with the Senior Consultant to the Afghan Resource and Information Centre.

At the beginning of the study, the researcher had a long discussion with a consultant appointed by the UN to look at the detailed aspects of how the common programming structure might work and a further meeting was held with this consultant and with Michael Keating on his return to London. The researcher also attended a presentation at the ACBAR General Assembly on the proposed monitoring and evaluation process and was able to participate in the meeting of the Afghanistan Task Force held on 5th July. In addition, informal meetings were held with a number of UN staff in both Islamabad and Peshawar. 


\section{FINDINGS}

(a)

\section{THE CONTEXT}

NGOs have been operating in Afghanistan since the early 1980s. Over that period, they have moved from being primarily providers of relief assistance through a phase, lasting broadly from 1989 to 1995 , in which the focus was on the rehabilitation of areas of refugee return to, over the past couple of years, an increasing emphasis on integrated community-based programmes. In addition, specialist services have been provided to both rural and urban populations relating to health, water supply, sanitation, agricultural support, veterinary care, disability and de-mining.

The primary objective during the period of Soviet occupation was to support communities still left in Afghanistan so as to minimise further outflows of refugees. Following the Soviet military withdrawal, all efforts were concentrated on the reconstruction of Afghanistan in order to facilitate the return of refugees from Pakistan and Iran.

Up until the fall of the Najibullah Government in April 1992, very little attention was given to the urban areas, which continued to benefit from Soviet subsidies. This imbalance was rectified over the following year with the establishment of public health and education programmes in Herat and, to a lesser degree, in Mazar. However, the conflict which erupted in Kabul immediately after the Mujahidin takeover made it impossible to operate programmes there on any scale until the summer of 1995 and this conflict also led to large-scale displacement. An important element of the aid process has, therefore, been to support the hundreds of thousands of displaced people within Afghanistan.

As indicated above, the thinking of both NGOs and UN agencies has moved on over the past year or so, so that greater attention is now being given to the spontaneous efforts of those living in the villages and neighbourhoods of Afghanistan and to a consideration of how these can best be supported. Innovative programmes have been established in Kabul, Mazar and Bamyan aimed at a strengthening of indigenous capacity within the urban environment and the greater peace and security which has prevailed in southern Afghanistan since October 1994 has enabled agencies to take a more long-term view of programming in support of rural population.

The operating environment has never been easy and has been affected by localised conflict at different periods in different areas and by a politicisation of traditional values such as to constrain access to women beyond the already conservative norms prevailing in Afghanistan. This politicisation has, in recent months, resulted in growing tensions between the Taliban and both UN agencies and NGOs and in increasing efforts on the part of the Taliban to control the activities of both groups of agencies. The principles of agencies have thus been tested to their limits and agencies have been engaged in intense debate as to how best to respond.

\section{COMMUNICATION WITHIN THE NGO COMMUNITY•}

A significant number of NGOs are members of ACBAR, which is able to provide a range of information services, in conjunction with the Afghan Resource and Information Centre. It also brings NGOs together to discuss both sectoral issues-and issues relating to particular geographical areas. In addition, ACBAR represents NGOs in relation to the presumptive authorities in Afghanistan, the Government of Pakistan and the UN system.

Afghan NGOs are also represented through the Afghan NGO Coordinating Body, which has a limited training and capacity building role. Its primary objective is to ensure that the interests of Afghan NGOs are taken on board within the wider aid community. Although a majority of ACBAR members are Afghan NGOs; the Steering Committee of ANCB takes the view that the existence of a separate body to represent 
Afghan NGOs is nonetheless of value. Many Afghan NGOs are represented on both bodies, including some of the larger Afghan NGOs.

Islamic NGOs, which are relatively few in number, although significant in resource terms, meet through the Islamic Coordination Council. This forum enables the fourteen member agencies to jointly reflect on what are broadly similar programmes with a common perspective, relating to emergency relief, education, health and the provision of support to orphans and widows. ICC also organises workshops, seminars and training sessions on capacity building and emergency preparedness. Most of these NGOs only operate in the refugee camps in Pakistan and in the eastern provinces of Afghanistan but they respond to emergencies throughout Afghanistan such as the recent earthquakes. Only one Islamic NGO, ISRA, is a member of ACBAR.

There are ongoing discussions between ACBAR, ANCB and ICC regarding their respective roles and areas of operation and there is no significant duplication of services. There has also been some discussion around the question of a possible merger but both ANCB and ICC are clear in wanting to maintain their separate identities.

It should be emphasised, in this regard, that the continued existence of four coordinating bodies, taking account also of the Kandahar-based SWABAC, should not be seen as indicating that the NGO community is divided. In fact, there is ample evidence that there is a high degree of coordination and cooperation between Afghan and non-Afghan NGOs, both in the field and in Pakistan. It is, however, necessary for ACBAR to take account of differences in the cultures, mandates and programmes of its member agencies and to achieve a balance, to the best of its ability, between these in seeking to represent NGO interests. This is inevitably a difficult task. There is still scope for a greater level of recognition amongst international NGOs of the professionalism and expertise that exists within the Afghan NGO community.

It is important to note that there are many mechanisms through which NGOs meet, both formally and informally. Thus, in addition to the sectoral and geographical working groups that exist under the ACBAR umbrella, there exist consortiums of agencies working in particular geographical areas. One is the European Commission - initiated integrated community-based programme which brings together eight EU-funded agencies to work in designated districts of Nangarhar, each providing a specialist input. Another is an initiative centred on Ghor, which brings together a group of Afghan and international NGOs to develop a long-term integrated programme. There are also many examples of agencies cooperating on logistics, notably the four Scandinavian NGOs and the NGOs tackling the aftermath of the recent earthquakes. British NGOs meet regularly at the headquarters level to discuss the broader issues relating to their programmes. European NGOs meet periodically, also at the headquarters level, through the Bonn Group, to discuss potential areas of greater cooperation, particularly in relation to EU-funded programmes. There is, therefore, a strong commitment to joint working and this has been demonstrated in relation to the present crisis with the Taliban where one agency after another interviewed for this study stated that they would take their lead from ACBAR,

This is not to say that divisions do not exist within the NGO community - only that these are less apparent than they have been in previous years and that good progress would appear to have been made since the Ashkhabad Conference, with donor encouragement.

\section{COMMUNICATION BETWEEN NGOS AND UN AGENCIES•}

The relationship between NGOs and UN agencies has been, to a degree, affected by the use of particular terminology, some of which has taken on pejorative implications. It may, therefore, be helpful if some definitions are first attempted. 
Some NGOs operate under contract to the UN. In some cases, this is to provide a service relating to health and water supply, for example. In others, the NGO is used, to all intents and purposes, as a building contractor. The terms "contractor" and "implementing partner" have been used loosely to describe both kinds of arrangement.

For the purpose of achieving greater clarity, it may be more appropriate to use the term "implementing partner" to describe a contractual arrangement in which the NGO provides a service. However, we still have a potential problem with definitions in that "implementing partner" is often used to signify that the NGO is simply used to do the UN's bidding, that the NGO does not have a creative role in terms of strategy planning and policy formulation. In referring to "implementing partners" below, the researcher is allowing for such a creative role. However, it may be that a new term, such as "operating partner", as is suggested below, might be more appropriate for a relationship in which the UN and NGOs engage in joint policy making and planning even though there may be a contract between them.

The key mechanisms whereby NGOs communicate with UN agencies are as follows:

(a) UNICEF provides funding and supplies to NGOs operating EPI, education and water supply programmes.

(b) UNOPS has used NGOs as contractors to undertake construction work relating to irrigation system, flood protection and water supply structures. It may also have used NGOs with a developmental focus as implementing partners rather than contractors but it was not possible to clarify this.

(c) WFP has used NGOs as contractors to undertake construction work relating to irrigation and flood protection structures and for road and bridge repair, through food for work programmes. Developmental NGOs have also entered into contracts with WFP as part of wider programmes funded by other donors.

(d) WFP has used NGOs as contractors to implement its bakeries programme in urban areas.

(e) WFP provides small quantities of wheat to NGOs for institutional feeding programmes.

(f) UNHCR uses NGOs as implementing partners for programmes in the refugee camps in Pakistan and for Quick Impact Projects in Afghanistan.

(g) UNDCP uses NGOs as implementing partners for crop substitution programmes.

(h) CDAP of UNOPS uses NGOs as implementing partners for its disability programme.

(i) FAO uses NGOs as implementing partners for veterinary programmes. It also provides technical support relating to horticulture, seed quality, reafforestation, veterinary care and animal husbandry. FAO is responsible for the production of improved seed, a task which used to be carried out by the Swedish Committee for Afghanistan.

(j) WHO provides technical support, particularly relating to TB control, and also supplies some specialist drugs.

(k) UNOCHA uses NGOs as implementing partners for the mine clearance, mine surveying and mine awareness programmes.

(1) UNOCHA operates planes for travel within Afghanistan which are available for use by NGO personnel. These benefit from a subsidy by the Danish Government. 
(m) The UN provides a security umbrella for all agencies operating in Afghanistan.

(n) UNOCHA consults NGOs on major strategy reviews, primarily through ACBAR, ANCB and ICC. There is an increasing NGO presence on the Afghanistan Support Group and on the Afghanistan Task Force.

There is a mixed picture here. Many NGOs referred to outstanding individuals within the UN system. The news that Alfredo Witschi-Cestari was to move on to another post was viewed with very considerable regret. The energy and determination of Michael Keating in seeking to take the common programme forward also received much favourable comment. There was, thus a recognition that the UN leadership had worked very hard to involve NGOs in strategic planning discussions since the Strategic Framework Process was initiated.

It was, however, felt that there were certain characteristics of the UN system which, in spite of these efforts, hindered effective communication between the assistance actors and which could, potentially, undermine future eflorts to engage in common programming.

Foremost among these was the difficulty which the UN clearly faced in dealing with a collapsed state. It was noted that the UN system had been designed to work with governments and that it was never intended that it should effectively substitute for government and thus take on full responsibility for the provision of basic services to the population. As a consequence, it had seen its role as to do what it could to provide support to the bureaucracy and, in the face of a much weakened bureaucracy in Afghanistan, had looked to NGOs to supplement what the governmental administration could provide. This had resulted in NGOs taking on a major operational role yet the UN has not entered into this relationship with NGOs on the basis of an equal partnership but, rather, had adopted the term of "implementing partner". This had denoted a relationship in which the UN exercised full control and the NGO was simply implementing UN programmes under contract to the $\mathrm{UN}$, without a role in strategic planning or policy formulation.

It was felt that this contractual relationship had proved to be highly problematic. When UNOCHA was formed in 1988 and the UN system embarked on the reconstruction process, many NGOs had been operating programmes in Afghanistan for very many years. There was, therefore, a level of expertise and experience to be tapped and those possessing it did not respond well to the fact that the UN agencies appeared to have scant regard for their potential contribution to policy making. Tensions, therefore, quickly developed between the UN and the NGO community and these were felt to be a possible factor in the decision by UNOCHA in 1990 to encourage the development of Afghan NGOs as potential implementing partners of the UN.

There was concern that this experiment in capacity building had resulted in a mushrooming of Afghan NGOs and that the UN had not committed sufficient resources to enable these incipient NGOs to develop their skills and management capacity to the point where they could play a role in the provision of basic services. Many had limped from UN contract to UN contract, acting, to all intents and purposes, as building contractors Some were fortunate enough to receive intensive support through capacity building programmes organised by Norwegian Church Aid, International Rescue Committee, NOVIB and the Ecumenical Office. Others fell by the wayside.

Many of the Afghans interviewed for this study regretted that the UN had not been able to proceed in a more measured way in encouraging the development of new Afghan NGOs so as to incrementally strengthen capacity through a planned programme of long-term support. There was concern that Afghan NGOs had been unfairly labelled as "contractors" or "paper NGOs" as a result.

It was lelt, however, that the opportunity still existed to build the capacity of the Afghan NGOs that remained as a means of channelling the skills and expertise of the relatively small number of educated 
Afghans who had not migrated to the USA and Europe. Capacity building and training were, therefore, viewed as a high priority for Afghan NGOs, particularly the smaller ones. This was seen as complementary to a process through which ANCB would seek to differentiate between NGOs with a service or developmental model from those which might more appropriately move into the private sector as building contractors. Concern was also expressed, in this regard, that, in spite of efforts by ACBAR and ANCB to accredit individual NGOs on the basis of certain criteria, the UN was giving contracts to unaccredited NGOs without a track record and that this was laying them open to pressure from the power holders to appoint their own nominees.

The use of particular Afghan NGOs as building contractors and the somewhat hybrid nature of some Afghan NGOs, oscillating between building contractors and service providers, is thus an issue which raises strong feelings among the Afghan NGO community. Opinions on this issue amongst NGOs in general, and amongst UN agencies and donors, were, however, divided. There were some who felt that, while it was unfortunate that the UN's policy had led to the creation of so many NGOs, it was unrealistic to expect that all those presently in existence could be supported to develop into fully-fledged development NGOs. Further, there was much to be gained from encouragement of a strong private sector. There was also a risk that NGOs without a solid grounding in development methodology might unwittingly undermine the spontaneous self-reliance which existed within Afghan communities.

Others felt strongly that the assistance community had a responsibility to do what it could to build skills and capacity within the Afghan NGO community and to develop a range of skills so that, if a broad-based government did emerge in Afghanistan, there would be a core of highly educated and well qualified Afghans to provide the nucleus of a new administration.

Notwithstanding the efforts of the UN to create new "implementing partners", the pre- existing Afghan, Islamic and Western NGOs have continued to operate with independent funding and have continued to build on lessons learned from previous programmes to improve the quality of their work. This has been facilitated by a partnership with donors which has enabled them to plan more effectively, to strengthen their internal capacity and to review their areas of focus and their methodologies. There has, as a result, been the move away from rehabilitation, referred to above, towards an integrated community-based approach to reconstruction which donors have supported with two to three year funding agreements. Similarly, donors have encouraged NGOs with a sectoral focus to improve on the quality of their work, drawing on standards produced by ACBAR, WHO, UNICEF and FAO over the years. The success of this partnership approach was evident from the interviews undertaken for this study and examples are given in Appendix A.

NGOs have thus moved to a position where they represent a solid block of professional organisations with long experience in Afghanistan. In budgetary terms, they bring in a subtantial quantity of funding from the European Union, Western and Islamic governments and independent sources. While it did not prove possible to obtain a figure of estimated expenditure by the UN system in relation to Afghanistan, it is likely that the approximately $\$ 73 \mathrm{~m}$ which Western, Islamic and Afghan NGOs derive from non UN sources would put its expenditure roughly on a par with that of the UN system. If one excludes the estimated $\$ 10 \mathrm{~m}$ going to Islamic NGOs, it is interesting to note that, of the $\$ 73,321,429$ recorded as the totality of budgets of ACBAR member agencies (not taking account of funding from NCA,IRC and NAC which would involve double counting), only $\$ 9,884,215$ is provided through contracts with the UN. Of this, only $\$ 3,018,520$ is going to Afghan NGOs. In contrast, Afghan NGOs have received $\$ 8,657,665$ from non UN-sources, thus challenging the prevailing myth that Afghan NGOs are essentially UN contractors. While much of the nonUN funding granted to Afghan NGOs goes to a relatively small number, it is nonetheless important that one is aware of the complexities within the overall picture and does not fall into the trap of categorising whole groups of agencies. 
This reality also undermines the notion that NGOs, as a group, are merely implementers of UN programmes. In fact, the key players in terms of actual programmes on the ground are donors and NGOs working in partnership, with the UN in a support role. In spite of this, NGOs consistently expressed the view that, notwithstanding the greater efforts of late to involve them in strategic planning, they were still encountering an attitude of what can only be described as arrogance from many UN officials. One NGO representative described the UN as behaving like an elder brother in its relations with NGOs, noting that there was a tendency for it to undervalue and be dismissive of the potential contribution of NGOs to the determination of policy. Thus, although the UN leadership has worked hard to involve NGOs in policy making, the early history of the relationship between the two groups of agencies has left its mark and much more needs to be done to achieve an equal partnership. The replacement of the term "implementing partner' by that of "operating partner" would be helpful in this regard.

NGOs also expressed concern at other patterns which tended to manifest themselves in the relationship between them and the UN: the tendency for the UN to claim ownership of NGO programmes funded by them: the unfortunate practice of the UN poaching the senior Afghan staff of NGOs, whether intentionally or unintentionally, and the apparent view of some UN staff that it was appropriate for them to direct the detailed operations of contracted NGOs, irrespective of their track record. A number of examples were given: of UNOPS providing funding for a programme which an NGO had been operating for two years and claiming that it was a UNOPS programme: of a senior member of UNOPS staff being invited to visit the offices of an NGO to discuss possible cooperation and, in the course of the visit, offering a job to one of the NGO's most experienced engineers; of an FAO monitor giving detailed instructions to the staff member of a well-established NGO.

However, of greatest concern was the fact that the UN had negotiated the recent Memorandum of Understanding with the Taliban without consulting with the NGO community as to the possible implications for NGOs of the terms under negotiation. As a result, NGOs had been put under pressure by the Taliban to comply with terms which would put their staff at risk.

These concerns relating to the broader relationship between the UN system and NGOs were additional to specific operational difficulties experienced. Of particular note was the contractual relationship between WFP and NGOs in relation to food for work programmes. It was felt that food for work was a useful mechanism under conditions of acute poverty but, to be effective, it was necessary that the agreed quantities of food were available to recompense those who had given their labour. A number of agencies complained that they had been badly let down by WFP and that food had arrived with very considerable delays and seriously undermined their credibility with the communities with which they were working as well as exposing their staff to overt hostility. Some NGOs, as a consequence, were looking to altematives such as cash for work, even though this was potentially more complex.

It was of interest, however, that two NGOs working in Badakshan had had a very good experience with WFP, which had consistently met its contractual obligations to provide food to agreed deadlines.

FAO received both positive and negative comments. One NGO was full of praise for the technical support which FAO provided in relation to horticulture, improved seed production and vegetable growing. Another, a veterinary NGO, had found itself at odds with FAO over FAO's policy of requiring contracted NGOs to move towards a privatisation model by charging for their services. This had been complicated by the fact that its contract with another donor required that vaccines be given free of charge.

UNICEF was the object of more negative comment. The primary concern related to UNICEF's own erratic and unpredictable funding which meant that the necessary funding was not always available to support planned EIPI programmes. This was, at times, compounded by vaccines not being available when funding was present. It was noted that, for the national immunisation days, for which donor funding had been earmarked, the operations would run smoothly, with funding, vaccine supplies and immunisation 
programmes synchronising. Concern was also expressed that UNICEF were often not able to deliver supplies of cement and pipes to meet contractual requirements.

It was also worthy of observation that there appeared to be no dialogue of note between the agricultural development wing of UNOPS and the growing number of NGOs operating an integrated community-based model. By contrast, the Comprehensive Disabled Afghans' Programme within UNOPS worked extremely closely with disability NGOs. The model adopted by CDAP is of interest in that it employs a minimal number of UN staff who provide support to a network of staff employed by NGOs to provide services to the population. Communication with the NGO staff is highly consultative and participatory to the point where the UN gives very little direction but is primarily facilitative in style. The staff of the NGOs, therefore, act with a high degree of independence but they are nonetheless fused into the UN programme. This model is felt by CDAP to be a positive one in that it avoids the complexities which can arise in programmes which have large numbers of UN staff and also tackles the problem of salary disparity between UN staff and NGOs and so deals with the risk of the UN poaching NGO staff. The CDAP programme also benefits from a high degree of delegated authority from the UN headquarters in New York.

UNHCR generally came in for positive comment, both in relation to work in the refugee camps and in connection with the repatriation programmes, where a number of NGOs were working closely with UNHCR to facilitate local reconstruction in areas of significant return.

The UN plane was found to be of significant value, although most NGOs used the ICRC plane where possible because it was free and also travelled from Peshawar. The security umbrella provided by the UN was also valued, although NGOs had, at times, felt that the UN was over-cautious in relation to security risks. This was obviously a matter of judgement but there were situations where NGOs had operated without a UN Security Coordinator present..Thus, a number of NGOs had returned to Mazar and the surrounding region ol late even though the UN was still absent.

The Regional Coordination Officers of UNOCHA were generally regarded positively as individuals. However, there was a fear that, if the common programming process was led at the regional level by RCOs, the notion of the UN as leader and of NGOs as contractors could be perpetuated.

It must be emphasised that this ambivalence towards the UN system did not ignore the very real efforts of key UN staff, such as the UN Coordinator, to involve the NGO community in policy making and to consult widely. It was, nonetheless, felt that it had required superhuman efforts on his part and on the part of his colleagues to achieve a small departure from normal UN practice and there was a fear that the UN system would revert to its traditional patterns after his departure. It was, therefore, of extreme importance for his successor to build on the greater involvement of NGOs which he had initiated.

\section{RELATIONS BETWEEN NGOS AND DONORS}

Apart from difficulties arising from late payments and unexpected gaps in funding, this was seen as a very positive relationship by NGOs. The European Commission, for example, played a key role in bringing agencies together on both a geographical and sectoral basis and in seeking to achieve policy cohesion and adherence to common standards and processes. This was facilitated by the presence of EC representatives in the field and by the creative role that they were able to play. Similarly, donor NGOs, such as NCA, NOVIB, the Ecumenical Office and IRC, were playing an important role in strengthening the capacity of Afghan NGOs in particular, through an intensive partnership described as "accompaniment". This denoted a process whereby the donor NGO would commit itself to provide support to a given NGO over a number of years and identify and seek to meet its particular needs relating to the building of management, financial and programming capacity. 
The role of donors in stregthening the capacity of Afghan NGOs is an important one. As indicated above, there is concern at the consequences of the earlier policy of the UN of encouraging the creation of Afghan NGOs without providing adequate support for their capacity-building and a clear view that donor support should be sought for a strengthened capacity-building process. The particular skills identified on which training and "accompaniment" were required were management, accounting and programming.

It was noted that, because of increasing donor requirements to justify funding and to ensure programme effectiveness, NGOs were spending an increasing proportion of their time on the preparation of reports for funders. However, NGOs did not feel that donors were imposing unreasonable constraints on their operations and valued their active involvement in the planning, monitoring and evaluation of programmes. Similarly, there did not appear to be any difficulties in relation to principle-centred programming save that a number of NGOs were encountering increasing difficulties in justifying continued funding for Afghanistan to donor governments in the face of a deteriorating human rights situation. NGOs tended to take on board the key areas of principle of individual donors in their planning of programmes and donors respected the fact that most agencies were reflecting carefully on how their own mandates and the principles of donors could best be put into practice. NGOs generally felt that their donors would back them if it became necessary to take a principled stand and there had been examples where such backing had been given. The researcher did not come across any NGOs which were not having serious regard to operating principles, although some, by virtue of the nature of their work, were not being particularly challenged in this respect.

\section{RLLATIONS BETWEEN NGOS AND PRESUMPTIVE AUTHORITIES/POWER HOLDERS}

This relationship was very much linked to the relationship which the UN had with the presumptive authorities/power holders although there were subtle differences. Generally, as noted above, the policy of the UN has been to replicate its normal practice of working with the structures of the state. This has not been a problem in the north of Afghanistan where the various presumptive authorities/power holders have not placed any obstacles in the way of UN operations. However, in the Taliban-controlled areas, the UN has faced the serious dilemma that it is having to work with a much weakened state bureaucracy, which is experiencing a continuing haemorrhage of its technical staff, to the point where UN agencies, ICRC and NGOs combined are taking the major responsibility for the provision of basic health and public health services, yet it is facing severe restrictions on its access to half the population. The UN has used the various UN conventions to guide it in its responses to this situation and NGOs have drawn on the mandates and operating principles of their individual organisations. However, the differential interpretation of what are broadly similar principles has led to the UN undermining NGO operations, and vice-versa, in relation to the Taliban.

The policy on what is often termed "institution-building" has proved to be the most problematic. A number of UN agencies, notably UNCHS, WHO and UNICEF, have taken the view that they should do what they can to maintain the capacity of the administrative structures of state within Afghanistan so that, when a national government does emerge, it has an administrative foundation to work with. To this end, they have sought to strengthen particular governmental structures such as the Ministry of Public Health, the Municipalities and the water supply departments. A number of NGOs have also opted for this approach, including SCF (US), MDM, CARE and Solidarite. The assistance provided has included, in the case of the UN agencies, the supply of vehicles and the use of government departments as contractors for the delivery of services. In the case of NGOs, it has been more limited, covering hospital refurbishment, the supply of equipment and support to waste clearance and water supply services. The policy of paying incentives to Ministry of Public Health staff, in order to keep trained medical staff in the public sector, is another important example.

This policy presupposes a partnership approach with the presumptive authorities and yet the Taliban have been committing very few resources to public sector services. A number of donors have, of late, expressed 
their serious concern that this responsibility is not being shared in any meaningful way by the presumptive authorities. It is of interest, in this regard, that, prior to the suspension of EC-funded programmes in Kabul which took effect on 18 th July, ECHO had insisted that its present contract with CARE and Solidarite to pump water in Kabul be the last and that the agencies negotiate a handover of responsibility to the Water Supply Department.

In all cases, the question of gender equity has arisen and divisions have occurred between agencies as to how far assistance should be given to a presumptive authority which, as an act of policy, places obstacles on the achievement of gender equity. It must be emphasised that this is not a consequence of agencies being divided, as has been stated in many quarters, into pragmatists and principle-centred actors. It was clear from this study that the vast majority of agencies are operating in accordance with gender principles. Where they have differed is in their interpretation of how these principles should be put into practice in the very unusual and challenging environment of the Taliban-controlled areas. However, these inconsistences have created some discord within the assistance community, in the sense that NGOs have differed in the extent to which they were prepared to compromise on their principles, and it would appear to be an important priority of common programming to achieve a degree of cohesion on gender principles. The UN could usefully draw on the policy positions drawn up by both international and Afghan NGOs to this end as considerable thought has gone into this issue.

Thus NGOs have formulated positions relating to their ability to continue to operate in accordance with their mandates, to the cost-effectiveness of programmes, to the severity of need, to the willingness of presumptive authorities and communities to take responsibility for the provision of resources, to human rights violations and to the safety of their staff. Some NGOs have suspended their programmes in response to these positions and, in a number of cases, have been able to renegotiate a resumption on more acceptable terms. Such decisions have never been taken lightly. Normally, the agencies concerned have reached a point where the constraints placed upon them have made it virtually impossible for them to meet the evident needs of the population and they have felt powerless in the face of these needs. The security of their staff has often been an added element.

A further and unintended problem which has arisen as a result of "institution-building" polices has been that some NGOs have been subjected to pressures from the Taliban to provide resources such as vehicles or "payments' to key individuals. In addition, arising from the fact that governmental structures have been used as UN contractors, for example the Municipality in Kandahar to operate a bakeries programme, the Taliban have come to view NGOs as competitors for UN resources. Certain NGOs interviewed for this study'stated that they had been put under some pressure from the Taliban to abandon their programmes so that the Taliban-controlled Ministries and Departments could receive UN and other donor funding to provide the same services. In making this assumption, the Taliban were appearing not to take on board the fact that most donors would be resistant to contractual relationships with a government which was not internationally recognised or with presumptive authorities which had explicit policies which ran counter to gender equity. Clearly, this is another important issue to which the common programming process needs to give urgent attention,

Another concern expressed was that the UN, in negotiating the recent MOU with the Taliban, had not appeared to take sufficient account of the possible risks involved, in a civil war situation, of UN agencies and NGOs giving the names and bio-data of their staff members. One NGO representative referred to the spate of assassinations, which took place in the early 1990s, of senior Afghan staff working for NGOs and feared that such information could be misused.

It was felt that the negotiating team had perhaps also not recognised that NGOs would be expected to follow suit. Because the Taliban had regarded the UN as taking the lead in relation to aid to Afghanistan, it had 'included the same requirement in a protocol being negotiated with the NGO community for the purpose of 
NGO registration. NGOs felt that they were much more vulnerable than the UN to pressures to employ staff put forward by the Taliban.

The question of relocation agreed in the MOU was another source of concern. It was felt that, because the UN was already used to its staff living in the same compound, it had, perhaps, not thought through the possible consequences of the much larger number of NGO staff being asked to live in a single compound, with all the potential security risks involved. References were made to the mob attack on the Shelter Now installations in Nasirbagh camp in Pakistan in the carly 1990s and to the more recent armed attack on the UN compound in Herat in the early part of 1997.

This negative experience had raised the question of whether negotiations with the presumptive authorities/power holders should be held jointly, with UN agencies, ICRC and NGOs participating. This is clearly a matter for further debate and would need to include a consideration of how individual agencies interact with the presumptive authorities outside a formal negotiation process

There was also concern that the UN, to the extent that it might be using NGOs or contractors linked to the Taliban, could be creating yet another situation in which NGOs not affiliated to the Taliban were viewed by the Taliban as competitors.

It is of interest to note that the UN agencies which worked most effectively with NGOs were those which did not have formal counterparts within the state bureaucracy, at least on any scale, such as FAO and UNHCR. The relationship with the presumptive authority was, thus, not sufficiently complex to impinge on relationships with NGOs,

NGOs were consistently of the view that dialogue had to be maintained with the Taliban, if at all possible, although many were concerned at the increasingly negative approach of the Taliban towards them and were unclear as to whether the Taliban sought their departure or simply wanted to exercise greater control over foreigners as, in their view, potentially corrupting influences. It was felt that NGOs should seek to retain a continued presence, even if it proved necessary to scale down operations.

Outside the urban areas, relations between NGOs and the presumptive authorities/power holders have varied over time and from area to area, with NGOs, at times, experiencing easy and positive relations with those exercising power at the local level and, at others, encountering significant levels of pressure and restrictions on their operations, their mobility and the movement of supplies. Some NGOs had come under considerable scrutiny, including efforts by the Taliban to check their financial records. This focus on agency accounts seemed to arise from rumours of possible corruption and also from a preoccupation with the possibility that agencies might be spending too much money on offices, vehicles and other overheads, at the expense of direct services. NGOs felt particularly vulnerable if it seemed necessary or desirable to dismiss members of staff. There had been many instances of dismissed staff seeking redress through the Taliban and of NGOs coming under pressure from the Taliban as a result. One NGO reported that they had been asked to vacate their offices, having refurbished them, and find new premises. It was thought that this might have arisen from the policy of the Taliban of seeking to regain possession of all premises previously held by the Government but there was also a feeling that the local leadership may simply have wanted to benefit directly from the refurbished premises or use the NGO to improve another building. As with this example, it has always been difficult to know what the particular factors have been in any given decision by the Taliban and, in particular, whether decisions have been politically motivated or have been geared to local self-interest.

NGOs varied in the degree to which their contacts with the presumptive authorities/power holders were through Afghan or international staff. Generally, the larger developmental NGOs would rely primarily on their Afghan staff, with the international staff only coming in for protocol purposes or where their contribution might help resolve a difficulty. At the other end of the spectrum, agencies employing expatriate 
volunteers, particularly in the medical field, were more likely to have international staff engaging directly with the presumptive authorities/power holders. The degree of contact with the presumptive authorities/power holders would depend very much on personalities. In one area, the Governor was said to call agencies together quite frequently to make requests for projects. In others, contacts were said to be sporadic.

In spite of the operating difficulties in Taliban-controlled areas, a number of NGOs with operations in the other parts of Afghanistan were thinking of establishing new programmes within the Taliban area in order to assert their neutrality.

\section{RELATIONS BETWEEN NGOS AND BENEFICIARIES}

Generally, it was the policy of NGOs to engage as fully with beneficiaries as possible. A significant and increasing number of NGOs were operating integrated community-based programmes, using a number of different models. All spent a considerable length of time in discussions with beneficiary structures, measured in months rather than weeks. Some used these discussions to simply identify what the priorities of the communities concerned were and to see to what extent they could meet these, as individual agencies or operating collectively, through initiatives relating to irrigation system repair, flood protection, water supply, improved seed, veterinary care and so on. Other NGOs sought to go beyond this by, for example, introducing new plant species or seeking to change animal husbandry practice through technical advice.

In some areas, agencies worked with the existing shuras or jirgas. In others, they sought to create new structures which would take responsibility for ongoing programmes.

In all cases, it was expected that beneficiaries would provide resources, mostly in the form of labour and locally available material, to complement the resources provided by the NGOs. The notion of shared responsibility was therefore a central element of communitybased programming.

Increasingly, NGOs were using Participatory Rural Appraisal or similar methodologies to supplement their discussions with beneficiaries. The survey reports produced by Afghanaid and DACAAR are noteworthy in this regard but there will certainly be other good examples.

Agencies such as MADERA which were seeking to facilitate refugee return had to engage in complex discussions with two sets of actors whose interests did not necessarily coincide. This involved separate negotiations with the potential returnees and those already living in the targeted villages and also included attempts to bring the parties together in one gathering.

DACAAR drew a distinction between its engagement with beneficiaries in relation to the integrated community-based programmes in which it is involved, where there is a prolonged interaction, and its well construction programmes, which tend to cover a large area. With the latter, there are discussions with potential beneficiaries to identify sites for wells and to also identify mechanics to be trained in hand pump maintenance. In this case, the prioritisation process is much simpler. There isn't, therefore, the need to weigh up agricultural needs against-water supply, health and education, for example, and to discuss questions of access. People know they need water and they accept that they will have responsibility for ongoing maintenance.

The Swedish Committee for Afghanistan noted that it would normally require communities to make a financial contribution to the costs of the education and health programmes which it supported. It added that it would only construct new schools in response to direct requests from communities and then only if there was an evident commitment to maintain the school. 


\section{DECISION-MAKING AND POLICY DETERMINATION PROCESSES WITHIN NGOS}

It appeared to be the norm that international NGOs enjoyed a high level of delegated authority from their headquarters and boards in Europe, the Middle East and North America. This included the determination of policy and the interpretation of organisational mandates and principles. The Pakistan or Afghanistan-based offices would normally only refer policy issues to their headquarters if they were of major significance.

Most international NGOs had decentralised their operations to field offices in Pakistan to the extent possible, with senior Afghan staff playing an important role in local decision-making. DACAAR, for example, noted that its regional staff had reasonable freedom within certain guidelines, standards and strategies, all of which were written down and absorbed through induction and training programmes. There was also a solid monitoring and impact assessment process.

Among the Afghan NGOs, consensual decision making and policy formulation was often practiced, particularly among the larger agencies. Periodic workshops were used to enable management staff to reflect on programme issues and plan operations. These tended to be held in Pakistan.

\section{THE ATTITUDES OF NGOS TOWARDS COMMON PROGRAMMING}

NGOs were generally positive about principle-centred common programming but had particular concerns at the fact that the process would be UN-led. It was felt that such a leadership role would have to be earned if it was to be effective. Otherwise, the process would be undermined by the underlying tensions between the UN system and the NGO community. The comment was often made that common programming was primarily aimed to achieve UN reform and there was concern that NGOs, which were, perhaps, more committed to coordination that UN agencies, could lose from the process.

As noted above, it was felt that the process would only work effectively if the UN was able to deal with NGOs as equal partners and involve them fully in policy determination and if the UN was to similarly ensure that the views of Afghans, working for the UN, for ICRC, for international NGOs and for Afghan NGOs were taken fully on board through their active participation in policy making. The NGO, CARE, usefully put forward the concept of a team to describe this relationship, contrasting it with the synchronisation which a command and control model seeks to create.

This ambivalence about a UN leadership role extended to the proposed leadership of the RCOs over the Regional Coordination Bodies. It was felt that the assistance actors in each region should be free to decide how best their various interests could be met through the RCBs and whether leadership should be on the basis of co-chairing, for example, or of length of experience in Afghanistan. Some NGOs advocated that the common programming structure should be led by a neutral figure and this may be an objective which is worth exploring. Others suggested that the person appointed should be directly accountable to the donor group.

There was a recognition that the characteristics of each RCB would be very much determined by the size of the local assistance community. Those based on Kandahar, Herat, Mazar, Bamyan and Faizabad were likely to be easier to manage in térms of their ability to appropriately represent the various interests than the RCBs in the eastern provinces, where there was a proliferation of agencies. There was a strong view that individual UN agencies should not sit, as of right, on each RCB, particularly if they played a relatively minor role in the region. There was an equally strong view among Afghan NGOs that they should be represented on each $\mathrm{RCB}$. The need for gender concerns to be mainstreamed was a further factor to be addressed. It was, therefore, likely that, in addition to the local ACBAR Coordinator, representatives of other agencies would be elected to reflect both these interests and the need for experience, with the UN representatives on the 
$\mathrm{RCB}$, in equal numbers selected on the basis of similar criteria. It was further proposed that donor NGOs such as NCA and the Ecumenical Office should be entitled to sit on the RCBs, in order to ensure that the capacity building of Afghan NGOs remained high on the agenda. It was assumed that donor government and EC representatives would attend to the extent possible. Considerable weight was attached to the value of the RCB incorporating those with longest experience in Afghanistan, irrespective of whether they were from the UN, NGO or donor communities, or from ICRC.

There were mixed views as to the size of the secretariat to be attached to the RCBs. Some NGOs felt that these needed to be sufficiently resourced to be effective. Others cautioned that one had to avoid the creation of large bureaucracies and a consequent loss of the informality which was a valued part of communication between agencies. It was felt, nonetheless, that the secretariat staff should have an outreach role so that they could obtain the views, and information on programmes, from agencies not represented on the RCB or unable to attend meetings. It is, therefore, likely, in practice, that the size of the secretariat attached to each $\mathrm{RCB}$ should reflect the size of the local assistance community. It was strongly felt that the senior staff member for each secretariat should be of a high calibre.

It was hoped that the RCBs would enable UN agencies, ICRC and NGOs to speak with one voice to the presumptive authorities when there were major problems, while allowing for day-to-day interaction between these authorities and individual agencies on non-contentious matters.

The question of local representation was seen as a potential area of difficulty.. Field-based meetings were more likely to involve those with local knowledge and contacts but those with decision-making power were more likely to be in Peshawar or Islamabad. The division between the UN in Islamabad and the NGOs in Peshawar did not help. Many agencies did not have staff in their regional offices who were authorised to make decisions on policy without reference to their Pakistan offices. It was felt that, to a degree, this could be overcome by Pakistan-based managers travelling to regional meetings but this was not likely to be always practical. Even if they did, they could not be sure that others attending, whether from the NGO sector or the UN, had the same degree of authority to make decisions. To the extent possible, therefore, greater authority had to be delegated to the field but the extent that it was desirable would depend on how much decisionmaking, as opposed to information sharing, was required through the RCBs.

Further, it was often difficult for field-based staff to find the time to attend coordination meetings. Operating conditions were often difficult and day-to-day administration and preparation of reports could be extremely, demanding. Burn-out was a common problem. Attendance at yet further meetings could, therefore, be problematic. There was, therefore, a case for looking at the mechanisms which already existed at the local level to achieve cooperation and coordination and build the RCB on these rather than automatically create new sub groups. It was felt that the focus should, therefore, be on mechanisms which NGO personnel already felt to be a priority. There was, however, a view that specialist working groups should be set up in each region to bring together NGOs and UN agencies working on the basis of an integrated communitybased model.

Staff turnover was another problem which needed to be addressed. This was said to be more acute within the UN system than amongst NGOs but it was certainly apparent within the NGO community. This was one of the strong arguments put forward by Afghans working in the assistance community for their greater involvement in policy making.

The practice of using expatriate volunteers was also felt to need some review as, while many had substantial experience and maturity, relationships within the assistance community and with the power holders could be upset by a single inappropriately placed volunteer It was felt that the recruitment process had to have serious regard to the difficult operating conditions, whether staff were salaried or had volunteer status. 
It should be noted that a number of NGOs proposed that donors should permit an allocation within agreed budgets to cover the additional time required for attendance at RCBs and the APB. They commented on the considerable amount of time they had spent on attendance at meetings relating to the Strategic Framework Process, the Assistance Strategy and Principle-Centred Common Programme and expressed concern that this time was not allowed for in budget planning.

The ambivalence of NGOs towards the control element of the proposed process extended to the Consolidated Appeal: Many agencies felt that it would certainly not be realistic to include all proposals in the 1998 Appeal and also questioned whether this was, in any event, the best system. It was noted that the Appeal normally raised only a proportion of the funding sought and that the Consolidated Appeal system made it difficult for the UN, which partly depended on this, to plan effectively. NGOs felt that, having built up relationships with donors to the point where it was possible to plan two to three year programmes in some cases, it would be a retrogressive step to adapt to the highly imperfect Consolidated Appeal system. It was, nonetheless, felt that donor concerns about cohesiveness and consistency could be met by using the Consolidated Appeal as an opportunity to report on and review overall funding for Afghanistan. Each RCB, with the help of its secretariat, would, thus, be asked to produce a report to accompany the Appeal which would commence with a situation and conflict analysis, to include a consideration of key issues relating to programmes, and go on to give a description of needs currently being met and of gaps in provision, a statement of the currently funded contributions of individual agencies and of their budgets for the current financial year and a list of possible new projects to meet identified gaps. Such a report would give donors an overview with which to assess applications for funding received on the basis of their own funding years. There was concern, however, that the Consolidated Appeal should not become too much of a straightjacket and that it should permit creativity within a clearly defined strategy.

Many NGOs saw the RCBs as of most potential benefit in the determination of overall strategy for the region, based on broad discussions on key issues, and in facilitating a long-term planning process. They could, thus, establish values and broad objectives and identify benchmarks.

There was also a suggestion that NGOs could use the RCBs to consult with other NGOs and appropriate UN agencies on their project proposals before they were submitted to donors.

It was further proposed that the determination of standards, appropriate unit costs, salary levels etc could be appropriately dealt with through working groups attached to the Afghanistan Programming Board. Where appropriate, these could be supplemented by sectoral working groups operating at the regional level to aim at uniformity within the field. However, agencies had to be realistic in considering to what extent uniformity could be achieved and to what extent it was necessary or desirable. This would always be a matter for negotiation, with some matters being less contentious than others.

The proposal to establish an independent Monitoring and Evaluation Unit was viewed very positively and this was seen as an important tool to ensure greater cohesion and consistency across the assistance community, particularly if the results were acted upon by donors, thus giving further teeth to the process. It was felt that this Unit should be directly accountable to the donor group.

The question of where control and enforcement functions should lie was subject to considerable debate. It was clearly felt that the RĆBs should be facilitative rather than controlling, while providing clarity to the process through the collection and dissemination of information. However, at the Afghanistan Programming Board level, there was a keen interest in how the relationship between donors, UN agencies, ICRC and NGOs would evolve in that a limited number of key donors were in a position to decide how best the needs of Afghanistan could be met through an appropriate use of the resources and skills which each assistance element could provide. It was, nonetheless, recognised that the donors were not presently constituted to do more than come together periodically to discuss broad issues. They were not, thus, in a position to exercise 
detailed control. However, because of the reluctance of NGOs to submit to the control of the UN system, it was felt that, to the extent possible, leadership of the aid process should be shared between donors, UN agencies, ICRC and NGOs through joint policy making. The model adopted by CDAP, whereby the UN supports a highly consultative and participative process, is one possible model which might meet the requirement of donors that the common programming process be UN-led while minimising the more negative effects of a command and control model. Donors could add teeth to the process by coming together on an ad-hoc basis to consider particular problem areas in the relationship between assistance actors. However, this model could raise questions as to where creativity in programming would most appropriately lie. One NGO expressed concern that common programming might stifle innovation.

There was some debate as to whether certain areas of work belonged more appropriately to the Afghanistan Programming Board than to the regional structures. The planning of water supply, health care, education, disability and veterinary services, for example, was seen to require both a national and a regional focus. Policy making was felt to be more appropriate for working groups attached to the APB whereas considerations of coverage might be better dealt with in the regions. Much depended on the number of actors involved at the local level. Often, informal contact between two or three actors might be enough.

It was felt that discussion on human rights issues belonged more appropriately to the APB and that a sub group should be established with consultative status. It was also proposed that a sub group be created to tackle gender issues but it was not clear how the terms of reference might relate to that on human rights. A further possible sub group, to look at environmental issues, was suggested. In addition, the possibility of an Afghan Advisory Board, to bring together individuals of standing from the Afghan staff of UN agencies and NGOs, and from civil society, was being explored.

In terms of priorities, NGOs were of the view that much progress had been made over the years, and particularly since Ashkhabad, with the active participation of donors, in achieving a greater level of coordination between humanitarian agencies. Common programming was seen as a useful mechanism for building on this over time. However, NGOs felt that the immediate priority was that principle-centred common programming should be used to achieve greater cohesion and consistency between the assistance actors in their relations with the presumptive authorities/power holders and this required that both donors and NGOs were involved in key policy decisions.

\section{OPPORTUNITIES AND CONSTRAINTS ON PARTNERSHIP}

This immediately raises the question of the relationship with the presumptive authorities/ power holders in a context of demand-led programming. To date, both NGOs and UNOPS have sought to engage with rural communities, with UNCHS providing the major link with urban neighbourhoods. It has proved possible to establish mechanisms and methodologies which have facilitated thorough discussion between NGOs/UNOPS and village structures. These discussions have resulted in agreement on priorities, on the resources needed to meet these and on the responsibilities which NGOs/ UNOPS and local structures will respectively take. There is, therefore, an acceptance that it is the community which is responsible for its own future and that it must demonstrate that responsibility by contributing resources to agreed programmes. The NGO/UNOPS simply strengthens the community to meet its responsibilities.

In this role of supporting community initiative, NGOs and UNOPS are effectively taking on a responsibility which would normally belong to a local authority. This is necessary because the existing local authorities are not allocating resources on a sufficient scale to provide effective support. The question then arises as to whether NGOs or UN agencies should work in partnership with the local authorities. In this context, one may regard the administrative structures in Kabul as primarily those of a local authority in that their remit does not extend much beyond the provision of a few services in the capital. 
There are two primary obstacles to an effective partnership with local authorities. First, it is reasonable to expect that, just as village and neighbourhood structures should accept responsibility for the provision of resources to meet priority needs, so local authorities should demonstrate that they have a concem to meet the basic needs of the population relating to agricultural production, health, water supply and education. At the present time, the local authorities through Afghanistan are, at best, accepting a minimal level of responsibility, which may include an advisory role, while, at the same time, earmarking a level of resources to military purposes which is not consistent with the wish of the population to enjoy peace and security.

The second obstacle to effective partnership and it is one which is only evident within certain defined geographical areas is that, not only are local authorities impeding access to a significant section of the population but they are also seeking to impose a degree of control over NGOs and UN agencies which is undermining of their effectiveness.

There are, of course, considerable local variations and these depend on a number of complex factors such as personality, local power relationships and the historical involvement of particular NGOs in the areas concerned. Thus, while it is reasonable to be concerned at what may be perceived as undue levels of control by certain authorities, it should not be assumed that the same patterns will repeat themselves from one area to another. Each will have its own nuanced picture.

However, NGOs, UN agencies and donors need to have regard to the demonstrated willingness of local authorities to play a positive role in relation to the provision of basic services in considering the extent to which, in their view, it is reasonable and appropriate to act in partnership with them. In so doing, they would, of course, have to take on board human rights principles as well as resource issues. While it may be unrealistic to secure resource allocations on the part of the authorities on any scale, a commitment to facilitate access to services in a way which is consistent with the expressed needs and attitudes of beneficiaries, as well as to provide advice where appropriate without undue control, would represent a positive way forward.

\section{CONCLUSIONS RELATING TO COMMON PROGRAMMING IN AFGHANISTAN•}

There exists a complex relationship between five groups of actors - beneficiaries, presumptive authorities/power holders, NGOs, ICRC and donors. These groups of actors are inter-related in a situation where power is fragmented with a national state and there is no internationally-recognised government. The ground rules are therefore unclear. Discussions to date between donors, UN agencies and NGOs regarding the establishment of possible ground rules have determined that programming for Afghanistan should be demand-led. i.e. it should respond to the expressed needs of those living in the villages and urban neighbourhoods of Afghanistan and seek to strengthen their efforts to survive and, if possible, improve their socio-economic condition.

Given this situation, it is important that donors, NGOs, ICRC and UN agencies work together to respond collectively to these needs and to tackle the obstacles created by local authorities. This is what principlecentred common programming should be about. There has to be a relationship of trust between the four groups of assistance actors, and of mutual respect. Donors have to decide how their resources can best be used to build on the respective strengths of the UN system, of ICRC and of NGOs. UN agencies must respect NGOs as equal partners in the process and set aside the concept of NGOs as implementing partners or contractors. Within the smallest NGOs there are people with useful contributions to make to the policy making process.

As noted above, the funding going to NGOs through contracts with the UN is only a small part of the total and this contractual relationship is seen as largely unsatisfactory by NGOs, although some rely on it in the absence of more developmentally-oriented alternatives. If the partnership between donors, UN agencies and 
NGOs can be further developed, the use of UN agencies as intermediaries for the provision of donor government funding to NGOs should perhaps be kept to the minimum consistent with agreed policies and the potential value of individual UN agencies exercising a control function. The move by certain donors to provide NGOs with two to three year funding is an important contribution to the common programming process as it will enable NGOs to plan effectively and to build relationships with beneficiary communities on a flexible basis. Similarly, donors should be prepared to earmark reasonably long-term funding to those UN progranmes which are regarded as essential to the overall agreed programme. The present short-term and uncertain funding of the UN represents a major impediment to common programming. The researcher learnt that, not only were the UN Coordinator and three senior members of his staff about to leave but his other colleagues did not know whether they would still have contracts until the end of the year. It is impossible to plan under such conditions.

Donors also need to build a high degree of flexibility into their funding provision. It is likely that operating constraints related to political or military developments will dictate that programmes are scaled down periodically and then built up again when conditions improve. There is a serious risk that, when operating conditions are particularly difficult, as they are at present, donors will simply reduce funding and not make provision for a possible revamping of programmes if conditions change for the better.

These are the key issues relating to principle-centred common programming. The structures proposed, namely the Afghanistan Programming Board and the Regional Coordination Bodies, provide a useful mechanism for relationships between donors, UN agencies, ICRC and NGOs to further develop but it is the nature of the relationship which is crucial and this will determine both the degree of control which the bodies can exercise, in that control can only be exercised by a combination of consent and donor muscle, and their ability to deal with major problems such as the relationship with the presumptive authorities/power holders. It would appear from the discussions held with the many agencies involved with this study that a less hierarchical, more participatory and advisory role be given to the APB than is currently envisaged, with it advising primarily on the overall direction of strategy and programming issues. Similarly, the RCBs should limit themselves to information gathering, coordination and facilitation. Thus, the command and control element which is so strong within the UN system needs to give way to something more akin to the CDAP model.

Recent developments in Afghanistan, particularly with regard to the relationship between the assistance community and the presumptive authorities/power holders must be set against the very considerable amount of positive work which continues to be undertaken in Afghanistan. One hopes that this can continue and that the ability of communities to survive and thrive can be further strengthened. However, if this proves not to be the case, common programming provides a mechanism for the assistance community to await developments with patience, with an eye to the long-term, and to respond flexibly and appropriately to opportunities that may arise.

\section{SOME POSSIBLE CONCLUSIONS OF RELEVANCE TO UN PROGRAMMES IN OTHER CONFLICT ZONES}

One must be careful in drawing conclusions from one conflict area and assuming that these can be transferred to others. However, there are a few conclusions which one can tentatively draw.

The first is that the UN agencies need to be allocated budgets at a reasonable level in advance of the financial year in which expenditure is incurred so that they can plan effectively. This is even more important in conflict situations because of the unpredictability of events and the need for flexibility. 
Second, donors, UN agencies, ICRC and NGOs need to sit down together at an early stage in their intervention in a conflict situation to debate how their respective areas of expertise, experience, skills and resources can be put to best use. While recognising that donors are inevitably in a somewhat different relationship with the other three assistance actors than they are with each other, the partnership should be a relatively equal one.

Third, that strategic planning and policy making, down to the level of the region, should continue to involve the four groups of assistance actors throughout their intervention.

Fourth, that efforts to build the capacity of indigenous organisations should be well planned and adequately resourced.

Fifth, that the UN could possibly consider keeping its own role to the minimum, on the CDAP model, and trust NGOs to do more, in close partnership with donors. This would help to overcome the unwieldy nature of decision-making within the UN system and make the UN less open to criticism on account of the relatively high costs of its operations. To the extent possible, the funding of NGOs should be provided from non-UN sources as the need to oversee NGO contracts adds to the UN bureaucracy. The individual UN agencies could then focus on their particular areas of expertise and, with a reduced number of personnel, might be able to achieve greater cohesion within the UN family in relation to a given conflict.

Sixth, the UN could review its procurement procedures to see if these could be better adapted to the fluidity of conflict situations and the need to seize windows of opportunity that may arise. The use of food-for-work programmes, which can be an effective tool in a conflict situation, also needs to be reviewed so that these " can be used more appropriately and effectively, possibly using NGOs as operating partners rather than implementing partners.

Seventh, it should be recognized that work in a conflict situation requires particular expertise and skills. The use of staff on short-term contracts or of volunteers can result in inappropriate behaviour, or in interactions with local power holders being mishandled, and so aggravate a delicate situation. Similarly, the UN should not send career staff to conflict situations if they do not have the appropriate skills.

Finally, there is the evident need for further debate on a political level within the UN as to how assistance agencies should relate to non-governmental power holders, particularly where they control urban areas and thus assert themselves as authorities. The questions of whether power is exercised with responsibility and with due regard for human rights will need to be given particular thought.

\section{APPENDIX A}

\section{EXAMPLES OF NGO COORDINATION AND OF COORDINATION WITH THE UN SYSTEM}

(a) The Save the Children Alliance, which brings together SCF (U.S.), SCF (U.K.)

and Radda Barnen, reflects jointly on how their shared objectives and principles can be put into practice within the Afghan context. They are also part of the "Children in Conflict Group", which commissioned a study in 1997 on the impart of the conflict on children throughout Afghanistan. UNICEF is part of the group and was an active participant in the formulation of the study proposal.

(b) SCF (U.K.) provides training on primary health care to NGOs and UN agencies, as well as to the Ministry of Public Health in Mazar.

(c) Norwegian Afghanistan Committee works with IbnSinna, UNICEF and WHO on the EPI Programme. 
(d) Norwegian Afghanistan Committee works closely with Afghanaid, MERLIN and MADERA on local programming.

(e) Scandinavian NGOs cooperate on a day-to-day basis in Peshawar, particularly in relation to logistics.

(f) DACAAR is working with UNICEF to produce national guidelines for water supply and sanitation.

(g) DACAAR undertakes joint surveys and joint needs assessments with UNHCR and has also worked with UNHCR and other NGOs to draw up a joint strategy on group repatriation. Meetings between UNHCR and NGOs involved in the targeted repatriation programme are held in Jalalabad.

(h) DACAAR has undertaken joint PRA assessments with MADERA and German Agro Action, and shared the costs of consultants, in relation to an EC-funded programme.

(i) SCA works with MERLIN, MSF and ACTED on local programming in Badakshan.

(j) Health-based NGOs use the WHO Essential Drugs List and also cooperate through ACBAR on standards and quality control. It is felt that there is still scope to achieve greater consistency on standards.

(k) A health working group meets monthly in Jalalabad under the chairmanship of WHO.

(l) MSF brings agencies together in Jalalabad to discuss malaria control.

(m) Islamic Relief Agency works with MADERA and FAO on improved wheat and vegetable seed programme in eastern Afghanistan.

(n) Eight NGOs are working together on an integrated community-based programme in Nangarhar, under the umbrella of the European Commission (DG1) - MADERA, DACAAR, MSF Healthnet, Swedish Committee for Afghanistan, German Agro Action, Solidarite Afghanistan (Belgium), IbnSinna and Aide Medicale Internationale.

(o) MADERA has a contract with the ACBAR Survey Unit to employ two people full- time to monitor MADERA's programme by talking to beneficiaries.

(p) ADA and CHA have established a joint survey team in western Afghanistan and are working on the modalities of other possible joint arrangements such as training.

(q) MSF Healthnet has received a one-off supply of 100,000 bednets from WHO for 1998/99.

(r) WHO is organising a conference on malaria control on the basis of technical expertise provided by MSF Healthnet. 
APPENDIX B

\section{EXAMPLES OF COMMUNICATION BETWEEN NGOS AND ${ }^{*}$ PRESUMPTIVE AUTHORITIES/POWER HOLDERS}

(a) SCF (U.K.) has links with the Department of Education in Mazar with the objective of strengthening the formal education system.

(b) NGOs have negotiated a draft protocol with the Taliban Ministry of Planning.

(c) NGOs have to obtain permits for particular purposes from the various presumptive authorities/power holders.

(d) NGOs engage in discussions with the presumptive authorities/power holders with a view to improving access to services.

(e) DACAAR provides maps and documentation to the local administration after completion of well-digging projects.

(f) MSF Healthnet makes incentive payments to MOPH staff working on the leishmaniasis control programme but does not provide equipment or vehicles.

(g) At a large MOPH health unit in Jalalabad which specialises in malaria, MSF Healthnet provides technical support and training, WHO provides re-agents and drugs and the International Islamic Relief Organisation has refurbished the building and provided salaries for MOPH staff.

APPENDIX C

NGOS OPERATING ON THE BASIS OF AN INTEGRATED COMMUNITY-BASED APPROACH

Norwegian Afghanistan Committee

CARE

Afghan Development Association

Coordination for Humanitarian Assistance

MADERA

OXFAM

DACAAR

German Agro Action

MSF Healthnet

SCA

Solidarite Afghanistan (Belgium)

IbnSinna

Aide Medicale Internationale

Afghanaid

NCA

NOVIB

IRC

Ecumenical Office 


\section{APPENDIX D}

\section{LIST OF NGOS INTERVIEWED}

OXFAM

Save the Children (U.K.)

Norwegian Afghanistan Committee

CARE

DACAAR

Swedish Committee for Afghanistan

German Agro Action

ISRA

CHA

CCA

IRC

MADERA

ADA

CoAR

IbnSina

Afghanaid

MSF Healthnet

NCA

MSF Holland

Dutch Committee

SCF (U.S.)

Kuwait Joint Relief Committee

This report was prepared with financial assistance from the Commission of the European Communities. The views expressed are those of the NGO, and do not represent any official view of the Commission.

Peter Marsden

Information Coordinator

British Agencies Afghanistan Group

27 July 1998 


\section{EXECUTIVE SUMmary OF \\ the Central Highlands Common Program Workshop \\ BAMYAN UNIVERSITY \\ 21-22 JULY 1998}

The first Common Program workshop in the Central Highlands was held at Bamyan University, 21-22 July, and brought together more than 70 representatives from UN, Afghan and international NGOs, local technical departments, and one donor (ECHO) to discuss objectives for the Common Program and forge a plan for its implementation in the region. The agenda included discussions about the principles and regional mechanisms for partnership, sectoral priorities, the role and composition of the Regional Coordination Board (RCB), monitoring and evaluation, the 1999 Consolidated Appeal, information gathering and sharing, and community participation. There was strong interest in the workshop and the Common Program initiative as evidenced by the support and encouragement of the regional commander and local technical departments.

It was clear from the workshop and numerous preparatory meetings in the region that sectoral Coordination Groups (a.k.a. technical working groups) could serve as the basic operational unit of the Common Program, linking the community, authorities, and the aid community. Coordination Groups in health, education, agriculture, infrastructure, relief, economy and community participation were formally established to prepare for the workshop and are open to all relevant international and Afghan NGOs, UN agencies, local technical departments, and community representatives. Before, during, and after the workshop, the Coordination Groups met to discuss their activities, map out their areas of operation, identify needs, define sectoral priorities, and discuss how to develop comprehensive and coherent sectoral programs in the region.

A significant outcome of the workshop was agreement on the functions, composition, and process of selecting members of the RCB. Echoing comments received about the Common Program paper, the workshop agreed that the RCB should facilitate coordination and not act as a gatekeeper by vetting proposals. Participants agreed that the primary functions of the RCB should be 1) to assist in the development of an aid strategy by supporting the sectoral Coordination Groups; 2) to assist in the gathering and sharing of information, including for the purposes of planning, monitoring, and evaluation; and 3) to act as a focal point for dealing with the authorities. There was also interest in the RCB as an advocate for the Central Highlands in the international aid community.

Finally, in a post-plenary meeting, Coordination Group chairs and interested UN, NGO, and donor representatives agreed on a formula for the composition of an interim RCB and the criteria for its members. This interim RCB will consist of nine members: two local technical authorities (i.e., the local health, education, and agriculture departments), two UN representatives, two Afghan and two international NGO representatives, and the Regional Coordination Officer (RCO) as an ex-officio member. Each of the groups will choose its two members and an alternate based on the following criteria: participation in the Coordination Groups, knowledge of the region, communication skills, geographic diversity, female representation, and commitment and ability to represent the people and needs of the Central Highlands. The functions of the Board will be supported by the RCO to the extent possible, including support for the selection of RCB members by facilitating communication with organizations outside Bamyan. Each of the groups agreed to submit the names of its RCB representatives to the RCO by Wednesday, July 29. 


\section{Minutes of the Central Higillands Common Program Workshop \\ BAMYAN UNIVERSITY \\ 21-22 JULY 1998}

\section{BACKGROUND}

Participants of the June 18 meeting in Peshawar felt that more should be done to prepare for a meeting about how the Common Program (CP) can be implemented in the Central Highlands. They agreed to schedule another meeting in the region 21-22 July and a Steering Committee was formed to draft an agenda and gather preparatory information. Angela Kearney, DRCO, and Huda Seif, UNDP, were tasked with chairing the Steering Committee, drafting an agenda, and gathering and distributing the necessary information. Huda visited the region in early July to clarify the objectives of the meeting while a followup meeting of NGOs took place in Peshawar to do the same. A draft agenda emerged from these consultations which formed the basis of the final workshop agenda.

Additionally, a number of Coordination Groups (a.k.a., technical working groups) were established to gather information about activities in health, education, agriculture, infrastructure, relief, economy, and community participation. Initially, these groups were comprised only of Bamyan-based representatives of UN agencies, Afghan and international NGOs, and local technical departments, but drew in organizations from other areas during the course of the workshop.

Before the workshop formally began, there was discussion about the name of the region, a contentious issue at the Peshawar meeting. The UN prefers to use the neutral term "Central Highlands" rather than the ethnic description "Hazarajat." Dr. Aziz of the local health department formally requested that the region be referred to as the Hazarajat or Hazaristan. Michael Keating suggested that the region be called "the Hazarajat" for the purposes of the workshop, but official UN documents would continue to refer to it as the "Central Highlands."

In order to make the workshop as inclusive as possible, all proceedings were translated into Dari/English, and Dari, Pashtu, and English versions of the CP document were made available.

\section{DAY 1: PARTNERShiP}

Setting the stage for the next two days of discussion, Karim Khalili, Secretary General of Hezb-i-Wahdat, opened the workshop with his frank opinion about the ineffectiveness of international aid organizations.

He acknowledged the geographic challenges posed by the region, but believes that inadequate assistance is more a consequence of the ineffectiveness of the aid community than the long winter and poor roads. Lack of interest in the region, fragmentation of the region into separate administrative parts, lack of familiarity of aid personnel with local knowledge and culture, and lack of monitoring and evaluation contribute to the ineffectiveness of the aid community in the Hazarajat. In conclusion, he offered his support to the aid community in the Hazarajat and his assurance that there would not be interference with the internal workings of assistance actors. He also encouraged the international community to work with existing local departments and help build their capacity to solve the region's problems.

Michael Keating set out the objectives of the meeting:

- To get to know each other;

- To agree on what kind of partnership we should have with the community and with each other and what mechanisms are needed to make that partnership meaningful; and

- To agree on our common objectives for the region. 
He gave a brief overview of the history of the CP: The January 1997 Ashgabat conference; selection of the Central Highlands as a pilot for the CP; and finally, comments received on the $\mathrm{CP}$ document to date. He stressed that selection of the Central Highlands does not necessarily mean that donors will give more money to the region. Donors, however, may look more favorably on any region that is able to formulate a comprehensive, coherent program, rather than submit "shopping lists" of projects.

He went on to address some of the common misperceptions about the CP: It is not an exercise to keep the donors happy, but a way to more effectively serve the people of Afghanistan. Using an analogy from an NGO response to the $\mathrm{CP}$ document, the $\mathrm{CP}$ is not intended to be a ballet with all dancers moving in scripted precision, but more like a football match with positions defined by players' strengths and weaknesses, and all working with a common strategy toward a common goal.

Examples were presented by aid organizations to demonstrate the opportunities and obstacles of partnership. Dominic Gentilhomme of Solidarites spoke about a multi-sector kitchen garden project among Solidarites, FAO, IbnSina, and the Community Fora. Some of the practical problems encountered by the partnership included salary differences and misunderstandings about the terms of the project. However, the organizations were able to work together to resolve these issues and their effectiveness was further enhanced by identifying and relying on each organization's respective strengths.

Madera thanked Oxfam and Avicen for their assistance in helping Madera get started in the region. Madera, in turn, helped Shohada, MSF, and CAWK with their operations. The lesson learned from this partnership is that commonality between organizations starts at the bottom, not at the top. Dr. Hasanyar of Oxfam spoke about the technical aspects of how Oxfam works with ECHO, UNOCHA, and the community in their seed distribution and land management programs.

Finally, Dr. Aziz of the Hazaristan Public Health Directorate gave an overview of a countrywide vaccination program implemented in Banyan district. This collaboration came about as a result of two failed vaccination campaigns in the region and resulted in the creation of a Provincial Management Team (PMT) for EPI made up of WHO, IbnSina, UNICEF, and the MOPH. As a result of the PMT partnership, the following vaccination campaigns were successful and he hopes to expand its coverage throughout the Central Highlands. According to Dr. Aziz, the criteria for success in partnership is collective decisionmaking, the close link between the PMT and the community; and that the PMT system is strong enough to survive the absence of any single member.

The plenary then broke down into smaller groups to discuss the practical obstacles to partnership, the principles that sustain a partnership, and how to make these partnerships work. A summary of the responses follows:

\section{OBStaCles to Partnership}

- Lack of overall vision .

- Lack of priorities

- Centralization of decision-making without regard to realties in the field

- Poor communication and information-sharing because of distance and lack of resources

- Selection of inappropriate technology

- Lack of confidence and trust between communities, authorities, and aid actors

- Lack of credible monitoring and evaluation

- Lack of feedback from the field to donors to allow them to make good decisions on time

- Corruption 


\section{PRINCIPLES OF PARTNERSHIP}

- Commitment to common goal, strategy, and policies

- Must agree on priorities

- Mutual respect and understanding

- Commitment to build capacity of assistance actors

- Community should be able to see the impact of cooperation

\section{How to Make Partnersiur WORK}

- Regular meetings to plan and monitor activities in sectors and the region

- Identify the relative strengths and weaknesses of actors and plan interventions accordingly

- Close working relationship with the community

- Rewards for cooperation, consequences for non-cooperation

Dinner was hosted by the Bamyan district Governor and prepared by the Community Fora. Workshop participants divided into four sectoral groups (health, education, agriculture, and infrastructure) to meet each other and talk about their activities in the region.

\section{Day 2: Sectoral COORDination Groups}

ECHO representative Sandrine Chopin spoke about donor interest in the $\mathrm{CP}$ as a way to achieve a greater vision for the country based on what people need as well as greater cost-efficiency and accountability for their contributions. The principles under which ECHO's assistance is given include assistance without discrimination based on sex, religion, or race; concern for the security and access of their partners; and emphasis on preventative assistance to avoid crises rather than "curative" assistance after a crisis has erupted. While donors want to see better planning, program design, and implementation, she admitted that donors must also be better coordinated.

Before the plenary divided into smaller sectoral working groups, Noor Akbari.of UNCHS gave a short history of the formation of the sectoral Coordination Groups. The groups formed in the sectors of health, education, agriculture, infrastructure, relief, economy, and community participation to prepare for this workshop and originally consisted of only Bamyan-based organizations. Each group was asked to formulate priorities, strategies, and information needs for their sector. From that, the groups tried to identify activities to implement their strategy in a way that would be transparent and involve the community. The infrastructure group, for example, decided to use the recent floods as a case study for coordination, and adopted a simple, open accounting system that would be posted on a board for everyone in the village to see. A few questions were raised about these groups, such as whether the groups would continue to meet after the $\mathrm{CP}$ workshop and how could the groups ensure participation by organizations outside the Bamyan area.

Sectoral working groups in health, education, agriculture, and infrastructure then met to answer two questions: What are the regional priorities in your sector and what is needed to support these priorities?

\section{AGRICULTURE}

Priorities:

Crops and livestock must be addressed simultaneously. For crops, wheat is a priority; for livestock, vaccination is a priority. Over-arching priorities in this sector are economic security and food sufficiency.

Support Needed: Better information-sharing: not just meetings but demonstration of best practices. 
HEALTH

Priorities:

Support Needed: Coordinating body for the health sector.

INFRASTRUCTURE

Priorities:

Because this sector impacts on all others, their priority was to develop a process by which the infrastructure groups can best address the priorities and needs of the other sectors.

Support Needed: Process by which to gather "bids" including criteria for selecting projects (e.g., cost, number of jobs created, impact on region, etc.), TORs for surveys, and submit proposals for funding.

\section{Education}

Priorities:

Unified curriculum; printing facilities; teacher salaries; school buildings; better coordination; teacher training; informal education; assistance to remote areas; and vocational training. (It was also noted that Bamyan University and some provinces had different priorities than these.)

Support Needed: Better communication between actors; regular meetings; better sharing of resources; means by which to avoid duplication; more community involvement; identify and define the role of assistance actors.

Samantha Reynolds of UNCHS, explained an idea that arose from a lunch discussion among the sectoral rapporteurs to address the common problem of lack of access in the region. She described a kind of CP "convoy" of organizations and programs that would start at one location and move through the region, addressing the priority needs of the communities it passed through. This convoy would not preclude the implementation of other projects or programs in the region, but would be a single coordinated effort to put the Common Program into practice. Jens Luneburg of OPS agreed that this was an effective method of addressing the access problem, adding that OPS takes a similar approach: going from one district to a neighboring district to implement projects rather than skipping districts. By planning projects in this way, security and access to their projects was guaranteed by the local commanders. There were some misunderstandings about where the convoy would start, but Mr. Jabarkhail of IbnSina disagreed with the convoy concept, saying that no matter where you started, those at the other end would suffer; similar to what happened with the PEACE initiative - the initiative began but ran out of steam before completion.

A number of short presentations about CP-related issues followed: Monitoring and evaluation, information-sharing and ProMIS, the Consolidated Appeal, and finally, the role of the Regional Coordination Board (RCB). Stacy Gilbert, UNDP, talked about the goal of monitoring and evaluation to increase effectiveness at the project level and now, with the Common Program, also at the regional and national level. Monitoring is an ongoing process by which one asks, "Are we doing things right?" and evaluation is standing back occasionally, looking at the impact of your intervention and asking "Are we doing the right things?" For example, what is the impact of a project to distribute improved wheat seed? Is it enough to measure how much more wheat was produced as a result? In order to know the impact of that project, one might look at farmers' household income - did their income increase because they produced more wheat or did their income decrease because there was surplus wheat on the market? Monitoring and evaluation should not only be done for projects, but also of regional programs and priorities (discussed later in one of the working groups). 
Hugh Williams spoke about ProMIS' role in identifying information and communication needs to assist in decision-making. One of the tools he is working on is using the Internet to communicate the needs of Afghans to donors and the rest of the world. The RCO added that organizations that don't have access to electricity or computers may also benefit by contributing their information for the ProMIS database and getting maps to help them in their planning. The ECHO representative expressed concern about the expense of this project versus other operational needs. Jawed Ludin of ACBAR emphasized the need for grassroots information-sharing so that organizations are not dependent on technology that can't be used in the field. To this end, ACBAR has produced a directory of organizations' activities in the Central Highlands and hopes to update it on a regular basis.

Highlighting the opportunity the upcoming Consolidated Appeal presents for common programming in the Central Highlands, Bradley Foerster, UNDP/UNOCHA, spoke of the need to transform the current shopping list of projects into coherent regional programs. Regional programs must go further than simply listing sectoral priorities, but should contain a strategy for addressing basic needs. Ideally, he would like to see the Central Highlands submit a regional program that meets, for example, the basic capacitybuilding needs of the health, education, agriculture, and infrastructure sectors for a specific amount of funding. If such a strategy were developed, he was confident that the chances for funding would be greatly enhanced. Though there are only a few weeks remaining to compile the information needed for the Appeal, a number of factors could be turned to the region's advantage: the groundwork already done by the Coordination Groups, relatively few actors in the region may facilitate coordination, and more opportunities for women and girls make funding this region more attractive to Western donors. The RCO offered to make her time and resources available to facilitate this process.

Michael Keating spoke about the proposed role of the Regional Coordination Board (RCB) in the CP document and comments received about the RCB from UN agencies, NGOs, and donors. The idea of the $\mathrm{RCB}$ as an organization to vet proposals was soundly rejected by all. Instead, three possible functions emerged from the comments: 1) to assist in the development of an aid strategy by supporting the sectoral Coordination Groups; 2) to assist in the gathering and sharing of information, including for the purposes of planning, monitoring, and evaluation; and 3) to act as a focal point for dealing with political authorities. One question that was raised about the RCB was the relationship between coordinating bodies such as ACBAR, ANCB, SWABAC, and the RCBs. Eddie Ndaga of UNICEF expressed concern that because most NGOs active in the region are actually based in Peshawar, decisions couldn't be made in Bamyan.

The plenary once more divided into smaller groups to discuss next steps on specific issues that had been raised during the course of the workshop: community participation; monitoring and evaluation; ProMIS; relief and contingency planning; $\mathrm{RCB}$ and the Appeal. The following is a summary of the proposed next steps in each area:

\section{COMmunity Participation -}

In order to develop good practice guidelines for community participation, an external evaluation of different community participation models should be undertaken. Criteria for such an evaluation should include equity, integrated program, good governance, and human rights, among others. 


\section{MONITORING AND EVALUATION}

Each of the following steps can be taken in each of the sectoral Coordination Groups:

- Define the level at which M\&E can happen (e.g., project-, sectoral-, regional-level);

- Develop a plan by which to monitor and evaluate at the appropriate level;

- Define the possible role of the RCBs in M\&E;

- Define criteria/standards/indicators;

- Establish control mechanisms.

\section{PROMIS AND INFORMATION-SHARING}

A number of questions need to be answered before next steps can be taken in this area:

- Can ProMIS support capacity-building?

- Will it increase or decrease the workload of field staff?

- What resources (manpower, time, software, money) are needed to keep it up-to-date?

- How can field staff access the data?

\section{Relief and Contingency Planning}

Pete Amolat of WFP underscored the urgency of relief planning now as the region will face a serious food deficit problem again this year and the movement of families to other areas has already begun. To prepare for the crisis, the following steps are being undertaken by the coordination group on relief:

- Establish lines of communication in advance;

- Agree on common strategies and define extra resources that can be used in a relief operation;

- Finalize list of resources, activities, requirements, and shortfall;

- Regular monthly meetings to review situation; convene extra meetings, as needed; and

- Prepare for rapid joint assessment of situation;

\section{REgional COORDINATION BOARD}

The plenary decided that decisions about the composition of the RCB should not be taken in a small group. A follow-on meeting on the topic was scheduled for the next day (see below).

\section{SUMMARY}

Wrapping up the workshop, Michael Keating reviewed the objectives of the meeting: to get to know each other; to agree on the principles and mechanisms of partnership; and to agree on common objectives for the region. While not perfect, he noted substantial progress toward these goals. He noted that it is easy to be cynical about the process, but that this is an opportunity to make the Common Program real. The workshop concluded with thanks to the numerous people and organizations involved including Bamyan University, the Community Fora, Hezb-I-Wahdat, the Governor of Bamyan, among others. 


\section{DAY 3: REgIONAL COORDINATION BOARD}

The sectoral Coordination Groups met the next morning to discuss further follow-up. Following those meetings, working group chairs and interested UN, NGO, and donor representatives met to continue discussion about the rolc and composition of the RCB. Stating that the role of the RCB as defined in the $\mathrm{CP}$ document was over-ambitious, Keating sees the sectoral Coordination Groups as the "primary building blocks" of assistance. Coordination groups, with support from the RCO, can serve as the practical link between the community, field practitioners, and the RCB. A number of issues arose during the ensuing discussion: The role of the sectoral Coordination Groups, the community, the RCO, and the Women's Committee on the RCB; how to ensure representation of remote locations; representation by an individual or an organization; the advocacy role of the RCB; possible operational functions for the RCB (e.g., M\&E, first point-of-contact with the community); and the need for a secretariat to support the board.

After some debate, participants agreed on a formula for the composition of an interim RCB and the criteria for its members. This interim RCB will consist of nine members: two local technical authorities (i.e., the local health, education, and agriculture departments), two UN representatives, two Afghan and two international NGO representatives, and the RCO as an ex-officio member. The board will be supported by the RCO, to the extent possible. Each of the groups will choose its two members and an alternate based on the following criteria: participation in the Coordination Groups, knowledge of the region, communication skills, geographic diversity, female representation, commitment and ability to represent the people and needs of the Central Highlands. The RCO will support the selection effort by facilitating communication with organizations outside Bamyan. Each of the groups agreed to submit the names of its representatives for the interim RCB to the RCO by Wednesday, July 29.

\section{NEXT STEPS}

In addition to the next steps outlined in specific issue-areas above, the following are actions suggested during the course of the workshop to advance the Common Program initiative in the Central Highlands:

- Local technical authorities, UN agencies, Afghan and international NGOs will submit the names of two RCB representatives and one alternate to the RCO by Wednesday, July 29.

- The RCO will convene a meeting of the interim RCB as soon as possible to discuss RCB role, responsibilities, and begin formulation of a regional program for the Consolidated Appeal.

- Based on discussions at the Bamyan workshop, a draft strategy for the Central Highlands will be prepared through the RCO and submitted to the RCB for their review.

- Coordination Groups will continue to meet to discuss and finalize their regional priorities, strategy, and sectoral programs for snbmission to the RCO. The RCO will facilitate the work of the Coordination Groups in formulating sectoral programs, lending whatever support is available for this effort.

- Coordination Groups will submit their priority infrastructure needs to the Infrastructure Coordination Group to be considered for inclusion in a regional infrastructure program within the next month. 


\section{ANNEX 1 \\ List OF PARTICIPANTS \\ Central Highlands COMMON PROgram Workshop \\ 21-22 JULY 1998}

\begin{tabular}{|c|c|c|c|}
\hline & Name & Agency & Function/Title \\
\hline 1. & Nafisa Nezam & UNOPS & Programme Officer - Islamabad \\
\hline 2. & Sharon Lash & UNOPS & Programme Officer(Health) - Isl \\
\hline 3. & Jens Luneburg & UNOPS & Senior Engineer - Islamabad \\
\hline 4. & Annie Begum & WHO & MCH Programme Officer - Islamabad \\
\hline 5. & Aman & FAO-Crop & Agriculturist - Yakawlang \\
\hline 6. & Taweechai $\mathrm{T}$. & UNHCR & Field Officer-Bamyan \\
\hline 7. & Peter Tamas & UNDP/UNOCHA & Consultant - Islamabad \\
\hline 8. & Hugh Williams & ProMIS/UNDP & Consultant - Islamabad \\
\hline 9. & Andrew Ross & ProMIS/UNDP & Consultant - Islamabad \\
\hline 10. & Dominic Gentilhomme & SOLIDARITES & Project Coordinator-Bamyan \\
\hline 11. & Alain de BURES & MADERA & Technical Director - Peshawar \\
\hline 12. & Ramazan MEHDIYAR & MADERA & $\begin{array}{l}\text { Provincial Director of Hazarajat - Behsud, } \\
\text { Wardak Province }\end{array}$ \\
\hline 13. & A. Shoukoor & WHO & EPI National Officer - Bamyan \\
\hline 14. & Nicholas Lawson & MSF-B & Field Coordinator - Panjao \\
\hline 15. & Ann-Sophie Gerin & MSF-B & MCH Coordinator - Panjao \\
\hline 16. & A. Ghafar & BRC & Director \\
\hline 17. & Anne Lancelot & UNCHS & Community Business dev. Officer - Bamyan \\
\hline 18. & Samantha Reynolds & UNCHS & Regional Program Manager - Bamyan \\
\hline 19. & Ali Bab Rasuly & Education Dept. & Head-Ghazni Province \\
\hline 20. & Mirzajan Janzad & Education Dept. & \\
\hline 21. & Abdul Hamid & Shurag Masajed & \\
\hline 22. & Dost Muhammad & $\begin{array}{l}\text { Sayed Adabad } \\
\text { Community }\end{array}$ & Community leader, Sayed abad - Bamyan \\
\hline 23. & Hussain Ali & UMA & Director-Yakawlang \\
\hline 24. & M. Hashim & UNOPS & OIC - Panjao \\
\hline 25. & Ali Reza Anwari & UNOPS & Engineer - Yakawlang \\
\hline 26. & M. Ismail Rayeen & IBN SINA & Regional Director - Bamyan \\
\hline 27. & Raz Mohd Wali & DHSA & Project Coordinator-Bamyan \\
\hline 28. & Ehsan A. Zahine & IBN SINA & Chairman - Peshawar \\
\hline 29. & Epco Hashrez & LEPCO & Medical Coordinator-Peshawar \\
\hline 30. & A. Hamid & WFP & Storekeeper-Bamyan \\
\hline 31. & M. Adel & PAR & Director - Yakawlang \\
\hline 32. & Rahila & $\begin{array}{l}\text { Women } \\
\text { Committee }\end{array}$ & Dy. VC Bamyan University \\
\hline 33. & M. Kazim Tura & \begin{tabular}{|l|} 
Bamyan \\
University \\
\end{tabular} & VC Bamyan University \\
\hline 34. & Sandrine Chopin & ECHO - Donor & Health Coordinator - Kabul \\
\hline 35. & Bradley Foerster & UNOCHA & Head of Program section - Islamabad \\
\hline 36. & Stacy Gilbert & UNDP & M\&E Consultant - Islamabad \\
\hline 37. & M. Khavari & Wahdat & Reporter-Bamyan \\
\hline
\end{tabular}




\begin{tabular}{|l|l|l|l|}
\hline & Name & Agency & Function/Title \\
\hline 38. & Don Sauer & DHSA & Technical Advisor - Peshawar \\
\hline 39. & Nik M. Ahmadi & CAWC & Director - Peshawar \\
\hline
\end{tabular}

\begin{tabular}{|c|c|c|c|}
\hline 40. & M. Ali & $\begin{array}{l}\text { Bamyan } \\
\text { University }\end{array}$ & Dean Faculty of agriculture - Bamyan \\
\hline 41. & Bakr Hussain & UNESCO & Programme Specialist (Educ) - Isl \\
\hline 42. & Amir Hassanyar & OXFAM & Reg. Program Mgr. - Panjao \\
\hline 43. & A. Sami Faiza & $\mathrm{CCA}$ & Program Officer - Banyan \\
\hline 44. & $\begin{array}{l}\text { Mohd Hussain } \\
\text { Rustamyan }\end{array}$ & $\begin{array}{l}\text { Hazarajat General } \\
\text { Education } \\
\text { director }\end{array}$ & Director - Bamyan \\
\hline 45. & Abdul Aziz Alimi & $\begin{array}{l}\text { Hazaristan Public } \\
\text { Health } \\
\text { Directorate }\end{array}$ & Director-Bamyan \\
\hline 46. & Noor Mohammad & $\begin{array}{l}\text { Education } \\
\text { Department }\end{array}$ & Director-Uruzgan \\
\hline 47. & Abdul Rahman & $\begin{array}{l}\text { Bamyan Edu. } \\
\text { Dept. }\end{array}$ & Director-Bamyan \\
\hline 48. & Hayatullah Hayat & $\begin{array}{l}\text { Hazarajat Agic. } \\
\text { Dept. }\end{array}$ & $\begin{array}{l}\text { President of Agric. \& Animal production } \\
\text { dept. }\end{array}$ \\
\hline 49. & N. S. Tunwar & FAO-Crops & OIC - Islamabad \\
\hline 50. & M. Abbas & NIDA & Program Manager - Bamyan \\
\hline 51. & M. Ali Barez & CFDO & Manager CFDO - Bamyan \\
\hline 52. & H. A. Naitaqi & FAO-Crops & NPPP Horticulture - Bamyan \\
\hline 53. & Mohd Ali & ARCS & Head of Branch - Bamyan \\
\hline 54. & Muslim & SHUHADA & Assistant Program Officer - Yakawang \\
\hline 55. & Eddie Ndaga & UNICEF & Assistant Project Officer - Peshawar \\
\hline 56. & Zia Moquim & $\mathrm{CCA}$ & Program Manager - Peshawar \\
\hline 57. & M. E. Zeerak & GRSP & Director-Ghazni \\
\hline 58. & A. Jawed Ludin & ACBAR & Program Manager - Peshawar \\
\hline 59. & Anwrul Haq & IBN SINA & Director-Peshawar \\
\hline 60. & M. Karimi & $\begin{array}{l}\text { International } \\
\text { Relation Dept. }\end{array}$ & Liaison Officer-Hebz-I- Wahdat - Bamyan \\
\hline 61. & Angela Kearney & UNOCHA/UNDP & DRCO - Bamyan \\
\hline 62. & Erasmus Ibom & UNOCHA/UNDP & Field Officer - Bamyan \\
\hline 63. & M. I. Bamiyani & UNOCHA/UNDP & Field Asst. - Bamyan \\
\hline 64. & Lisa Zarrabi & $\mathrm{ACF}$ & Nutritionist - Bamyan \\
\hline 65. & Lesha Singh & ACF & Food Security - Bamyan \\
\hline 66. & Noor Akbari & UNCHS & Program Assistant - Bamyan \\
\hline 67. & Mohd Mohsin & CAWC & Program Manager - Peshawar \\
\hline 68. & Mohammad Ismail & $\mathrm{ACF}$ & Agronomist - Bamyan \\
\hline 69. & Pete Amolat & WFP & OIC/HSO - Bamyan \\
\hline 70. & Ghulam Hassan & WFP & Asst. Field Officer-Bamyan \\
\hline 71. & M. Yunus & WFP & Asst. Field Officer - Bamyan \\
\hline 72. & Michael Keating & UNOCHA/UNDP & Common Program Advisor - Isl \\
\hline
\end{tabular}

